\title{
DE KELSEN A LA CONTRADICGIÓN DE TESIS 293/2011: LOS CONFLICTOS NORMATIVOS ENTRE JERARQUÍAS FORMALES Y DECISIONISMO*
}

\author{
FROM KELSEN TO THE CONTRADICCIÓN DE TESIS 293/2011: \\ NORMATIVE CONFLICTS BETWEEN FORMAL \\ HIERARCHIES AND DECISIONISM
}

Alberto PUPPO**

RESUMEN: El punto de partida de este trabajo es doble: desde una perspectiva teórica se cuestiona la relación entre las jerarquías normativas y las teorías sobre las relaciones entre sistemas jurídicos, y desde una perspectiva práctica se reconstruye la postura de la Suprema Corte de Justicia de la Nación respecto de la siguiente cuestión: ¿qué deben hacer los jueces cuando se enfrentan a un conflicto entre una norma constitucional restrictiva de derechos y otra internacional protectora de derechos? $\mathrm{Pa}$ ra formular una respuesta que no obedezca a meras ideologías se deben hacer varias distinciones: entre jerarquía y supremacía, fuentes y normas, normas y posiciones normativas, reglas y principios, y tomar en serio la ambigüedad de la noción de norma restrictiva de derechos. Dada la complejidad del cuadro que resulta de la combinación entre todos los significados posibles de las nociones clave, no sorprende que, más allá de las tesis publicadas, la pregunta toral no tenga respuestas correctas ni desde el punto de vista de la Constitución ni desde una
ABSTRACT: The starting point for this work is two-fold: from a theoretical standpoint the relationship between the hierarchy of norms and (monist or pluralist) theories regarding the relationship between legal systems is questioned, and from a practical standpoint, the Supreme Court of Justice's posture on the following issue is reconstructed: what should judges do when they are faced with a conflict between a restrictive constitutional provision restricting human rights and an international norm protecting them? To provide an answer that is not merely ideological, several distinctions must be made: between hierarchy and supremacy, between norms and normative positions, between rules and principles, and the ambiguity of human rights restriction must be taken seriously. Given the complexity of the result of the combination of all the key concepts, it is not surprising that, beyond the Supreme Court's published theses, neither the constitutional nor the international point of view provide the correct answer for the toral question. There will only be, on a case-by-case basis, more or less wellfounded decisions.

* Artículo recibido el 19 de noviembre de 2015 y aceptado para su publicación el 25 de mayo de 2016.

** Profesor asociado de tiempo completo, Departamento de Derecho, ITAM.

Boletín Mexicano de Derecho Comparado nueva serie, año XLIX, núm. 147, septiembre-diciembre de 2016, pp. 173-213

D. R. (C) 2016. UNAM, Instituto de Investigaciones Jurídicas. 
perspectiva internacional. Sólo habrá, caso por caso, decisiones más o menos bien fundamentadas.

Palabras clave: Jerarquía normativa, monismo, pluralismo, supremacía constitucional, derechos humanos.

Keyzerds: Normative hierarchy, monism, pluralism, constitutional supremacy, human rights.

SUMARIO: I. Introducción. II. Jerarquías normativas y supremacía constitucional: Je t'aime moi non plus. III. Fuentes, normas de derechos humanos y derechos humanos: ¿pirámides de arena? IV. Reglas vs. principios: la ambigüedad de las restricciones constitucionales. V. Monismo y pluralismo: entre teoría y derecho positivo. VI. Conclusión.

\section{INTRODUCGIÓN}

En 1974, el Boletín Mexicano de Derecho Comparado publicó varios textos clásicos kelsenianos, entre los cuales destacan dos de los más importantes textos sobre la aplicabilidad de la lógica al derecho: "Derogación" y "Derecho y lógica". ${ }^{1}$ En estos textos, publicados por primera vez en 1962 y 1965, Kelsen desarrolla la que se conoce como "última etapa" de la evolución de su teoría o etapa decisionista: la lógica o, más precisamente, el principio de no contradicción no aplica a las normas ni directamente ni - como había sostenido en la segunda edición de la Teoría pura del derecho ${ }^{2}{ }^{2}$ indirectamente, es decir, en virtud de su aplicación a las proposiciones normativas que describen las normas válidas. ${ }^{3}$

En el mismo número de la Revista se publicó uno de los pocos textos que H. L. A. Hart dedica expresamente a Kelsen, ${ }^{4}$ cuyo objeto principal es la tesis kelseniana de la unidad del derecho, y en particular la unidad entre derecho interno y derecho internacional. Según Hart, en Kelsen pueden

1 Traducidos por A. Ortiz, Boletín Mexicano de Derecho Comparado, núm. 21, septiembrediciembre de 1974, pp. 259-274 y 275-282, respectivamente.

2 Kelsen, Hans, Teoría pura del derecho, 2a. ed., trad. de R. Vernengo, México, UNAM, Instituto de Investigaciones Jurídicas, 1982.

3 Kelsen, Hans, "Derecho y lógica", op. cit., p. 281.

4 Hart, Herbert L. A., "Teoría de Kelsen sobre la unidad del derecho", trad. de R. Tamayo y Salmorán, Boletín Mexicano de Derecho Comparado, núm. 21, septiembre-diciembre de 1974, pp. 105-140. 
distinguirse dos tesis monistas: una "débil" (descriptiva) sobre lo que el derecho positivo es, y una "fuerte" (epistemológica y/o normativa) sobre cómo la ciencia del derecho debe conocer su objeto. Mientras la primera es una hipótesis cuyo poder explicativo depende de la realidad, la segunda es, en la Teoría pura del derecho, una tesis necesaria, dado que sólo es la otra cara de (la tesis de) la ausencia de contradicciones entre normas jurídicas válidas. ${ }^{5}$

Es necesario resaltar la relación, en la obra de Kelsen, entre elementos más conocidos y elementos menos conocidos, como este último. Un aspecto muy conocido que ha permeado la teoría constitucional es, sin duda, la idea de sistema jurídico como estructura jerarquizada, en donde las normas superiores regulan la creación de las normas inferiores. Una vez asumida tal estructura, para el juez adquiere una importancia capital la determinación de una jerarquía, ya que se supone que la norma inferior que no cumpla con los criterios establecidos por la norma superior puede ser anulada o por lo menos declarada inválida e inaplicada. ${ }^{6} \mathrm{El}$ principio jerárquico, dado que el derecho es concebido como un sistema libre de inconsistencias, resulta ser una herramienta particularmente eficaz.

Pero la noción de validez de Kelsen - y esto es menos conocido, quizá porque proyecta sobre el autor vienés sombras iusnaturalistas ${ }^{7}$ va más allá: una norma válida no es solamente una norma creada regularmente, sino también una norma que debe ser acatada, ya que "validez" significa, asimismo, fuerza obligatoria. La presencia de una contradicción normativa no sería sólo un problema lógico, sino también uno de carácter práctico, pues dos normas no pueden ser acatadas si exigen conductas incompatibles.

¿En qué sentido, entonces, la tesis epistemológica monista es la otra cara de la ausencia de contradicciones normativas? Si se asume que tanto el derecho interno como el derecho internacional son conjuntos de normas

5 Kelsen, Hans, Teoría pura..., cit., p. 331.

6 En el caso del derecho positivo mexicano, esto corresponde a las distintas facultades que tienen distintas jurisdicciones: en el contexto del control concentrado, la facultad de anular o de expulsar del sistema jurídico a la norma inválida, y en el contexto del control difuso, la facultad de dejar la norma inválida sin aplicación.

7 Ross, Alf, "El concepto de validez y el conflicto entre el positivismo jurídico y el derecho natural", trad. de G. Carrió y O. Paschero, en Ross, Alf, El concepto de validez y otros ensayos, México, Fontamara, 1997, pp. 7-32. Al respecto, para referirse a la postura kelseniana, Ross acuña la expresión "cuasipositivista". 
válidas y, por tanto, tienen fuerza obligatoria, la única forma de eliminar las contradicciones es concibiendo una única estructura jerárquica, en la cual todas las normas, tanto nacionales como internacionales, se acomodan. Para Kelsen, si se consideran a los dos sistemas por separado, sólo uno podría ser jurídico, esto es, un sistema de normas válidas, es decir, obligatorias. Su tesis es que los pluralistas - dado que es innegable el carácter jurídico de los derechos estatales - terminan negando que el derecho internacional es derecho; así las cosas, para los que defienden el carácter jurídico de las normas internacionales, la única opción es el monismo.

Tal conclusión kelseniana es exagerada, pues presupone algo que muchos autores positivistas rechazan, ${ }^{8}$ esto es, la noción de validez como fuerza obligatoria, pero pone de manifiesto la relevancia de la cuestión de las relaciones entre sistemas normativos al momento de enfrentarse a potenciales conflictos normativos, como el que inspiró la importante decisión de la Suprema Corte de Justicia de la Nación (SCJN) en la Contradicción de tesis 293/2011.

El punto de partida de este trabajo es, por lo tanto, doble: 1) desde una perspectiva teórica, su inspiración es la cuestión de la relación entre los conflictos normativos y las teorías (monistas o pluralistas) sobre las relaciones entre sistemas jurídicos, y 2) desde una perspectiva práctica, su inspiración es la postura de la SCJN sobre las relaciones entre normas constitucionales y normas internacionales de derechos humanos, y en particular sobre la forma de resolver eventuales conflictos entre ellas. ${ }^{9}$

8 Que las normas jurídicas tengan fuerza obligatoria sería más bien una tesis atribuible al positivismo ideológico, y no al positivismo metodológico. Sobre las distintas acepciones en que históricamente se ha usado la expresión "positivismo jurídico", véase Bobbio, Norberto, "Positivismo jurídico", trad. de E. Garzón Valdés, en Bobbio, Norberto, El problema del positivismo jurídico, Mexico, Fontamara, 2004, pp. 37-66.

9 Me basaré principalmente en la Contradicción de tesis 293/11 (en adelante CT), cuyo engrose es consultable en: http://wrew2.scjn.gob.mx/ConsultaTematica/PaginasPub/Detalle Pub.aspx?AsuntoID=129659. Los comentarios sobre esta decisión han proliferado. Entre otros, véanse Ortega García, Ramón, "El enfoque restrictivo de los derechos humanos: comentarios a la Contradicción de tesis 293/2011", Cuestiones Constitucionales. Revista Mexicana de Derecho Constitucional, núm. 32, enero-junio de 2015, pp. 265-291; Silva García, Fernando, "Derechos humanos y restricciones constitucionales: ¿reforma constitucional del futuro vs. interpretación constitucional del pasado? (comentario a la C. T. 293/2011 del Pleno de la SCJN)", Cuestiones Constitucionales. Revista Mexicana de Derecho Constitucional, núm. 30, enerojunio de 2014, pp. 251-272; Pou Giménez, Francisca, "Lo que quisiera que la Corte hiciera por mí: lealtad constitucional y justicia dialógica en la aplicación de la CT 293/2011", 
La cuestión teórica y la cuestión práctica resultan indisolubles, ya que la preocupación central en los debates entre los ministros de la Corte mexicana es, en definitiva, la siguiente: ¿qué deben hacer los jueces cuando se enfrentan a un conflicto entre dos normas: una constitucional y otra internacional de derechos humanos? La naturaleza de tal conflicto depende por completo de ciertas asunciones teóricas: la primera de ellas consiste en tomar una postura sobre si tal conflicto tiene el carácter de una contradicción lógica ${ }^{10}$ o de una suerte de conflicto entre fuerzas opuestas, para la resolución del cual la lógica es impotente. ${ }^{11}$ La segunda de ellas consiste en una cierta teoría sobre las relaciones entre sistemas normativos: dependiendo de si se adopta el monismo o el pluralismo, tal conflicto será considerado como un conflicto interno a un mismo sistema o entre dos sistemas.

Las dos asunciones teóricas son también indisolubles, por lo menos desde una perspectiva kelseniana. En efecto, después del abandono de la tesis de la aplicabilidad de la lógica a las normas, que confirmó el abandono del término "contradicción" y el uso ya sistemático del término "con-

en Sánchez Gil, Rubén y Caballero, José Luis (eds.), Derechos constitucionales e internacionales. Perspectivas, retos y debates, México, Tirant lo Blanch, en prensa.

10 En ningún lugar de la sentencia - ni en el engrose ni en los votos particulares y/o concurrentes - se habla de los conflictos entre normas en términos de "contradicciones lógicas". Una de las razones de este escrito es quizá aclarar lo que, si se toma en serio lo escrito por algunos comentaristas autorizados, nos deja perplejos. Por ejemplo, Ortega García - que quizá no ha leído con detenimiento a Kelsen, pero que en principio ha leído la sentencia de la Corte - no duda en hablar de "conflictos lógicos". Según él, la sentencia determina que "frente a un conflicto lógico entre una norma constitucional (restrictiva) y una norma de un tratado internacional (más protectora), deberá prevalecer invariablemente la primera" (op. cit., p. 266), lo que le permite concluir que la sentencia de la Corte "contradice a la Constitución" (ibidem, pp. 266 y 289, énfasis añadidos). La aplicación del adjetivo "lógico" a las relaciones entre normas, a pesar de haber sido abandonado por Kelsen y por la mejor teoría del derecho, parece haber sobrevivido; en este sentido, véase García Castillo, Tonatiuth, "La reforma constitucional mexicana de 2011 en materia de derechos humanos. Una lectura desde el derecho internacional", Boletín Mexicano de Derecho Comparado, núm. 143, mayo-agosto de 2015, pp. 645-696, donde se afirma lo siguiente: "Por sistema legal entendemos un conjunto de disposiciones jurídicas de alguna manera conectadas entre sí que tienen coherencia lógica en sus relaciones" (p. 648, énfasis añadido).

11 Según Kelsen, un conflicto de normas puede ser comparado con "dos fuerzas que operan en direcciones opuestas sobre el mismo punto" ("Derecho y lógica", op. cit., p. 279). En tal caso, la única forma para resolverlo es la eliminación de una de las dos fuerzas, esto es, la derogación de una de las normas en conflicto, su supresión, siendo expresión de una tercera fuerza y no una consecuencia lógica (Kelsen, Hans, "Derogación”, op. cit.). 
flicto", Kelsen en una nota de su obra póstuma, Teoría general de las normas, parece sugerir que si se abandona la tesis de la aplicabilidad de la lógica a las normas, ya no se tiene un argumento teórico para defender la tesis epistemológica monista. ${ }^{12}$

La finalidad del trabajo no es decir algo nuevo sobre lógica y normas ${ }^{13}$ o sobre monismo. ${ }^{14}$ Mi objetivo es más bien aclarar el sentido de la postura de la SGJN y proponer, indirectamente, una interpretación del artículo 1o. de la Constitución mexicana. A pesar de la importancia de las asunciones teóricas mencionadas, que sin duda determinan los términos en que se enmarcan los debates, es de sospechar que el problema práctico termine solucionándose a partir de decisiones interpretativas, cuyo sentido podría ser completamente independiente de las posturas teóricas asumidas. Esto es lo que parece revelar la lectura de la decisión de la Corte, ya que un serio debate teórico sobre pluralismo o monismo, fundamental al momento de afirmar (o negar) una relación jerárquica, es sorprendentemente ausente.

Antes de proceder a las necesarias distinciones es menester empezar por el comienzo, o sea, los dos párrafos fundamentales del artículo 10. constitucional:

Artículo 1o. En los Estados Unidos Mexicanos todas las personas gozarán de los derechos humanos reconocidos en esta Constitución y en los tratados internacionales de los que el Estado Mexicano sea parte, así como de las garantías para su protección, cuyo ejercicio no podrá restringirse ni suspenderse, salvo en los casos y bajo las condiciones que esta Constitución establece.

Las normas relativas a los derechos humanos se interpretarán de conformidad con esta Constitución y con los tratados internacionales de la materia favoreciendo en todo tiempo a las personas la protección más amplia.

12 Kelsen, Hans, General Theory of Norms, Oxford, Clarendon, 1991, nota 154, p. 394. Este autor reconoce que el hecho de que un conflicto entre normas "no es una contradicción lógica destruye mi tesis según la cual la unicidad del orden normativo válido para una determinada esfera es una consecuencia del principio de unidad cuyo criterio negativo es la imposibilidad de contradicciones lógicas" (traducción mía).

13 Todo lo relevante (y sensato) ya se ha dicho. Véanse, por todos, Gianformaggio, Letizia, "Sobre la deducción de la validez en Hans Kelsen", trad. de P. Larrañaga, en Gianformaggio, Letizia, Estudios sobre Kelsen, México, Fontamara, 1994, pp. 49-85; Losano, Mario G., "La teoría pura del derecho: del logicismo al irracionalismo", trad. de J. Ruiz Manero, Doxa. Cuadernos de Filosofia del Derecho, núm. 2, 1985, pp. 55-85.

14 Sobre el monismo kelseniano remito a "autor". 
Los debates entre ministros parecen versar, directa o indirectamente, sobre la existencia (o no) de una jerarquía entre normas constitucionales y normas internacionales de derechos humanos, y principalmente sobre las consecuencias de tal jerarquía (o de su ausencia), en el plano de la aplicación judicial del derecho. Algunos pasajes cruciales de la decisión de la Corte ilustran perfectamente la cuestión planteada y las resoluciones adoptadas al respecto. Tales pasajes conciernen esencialmente dos puntos: por un lado, la (ausencia) de jerarquía entre normas de derechos humanos expresadas por la fuente constitucional y la fuente convencional, en particular - aunque no exclusivamente - interamericana, y por otro lado, la afirmación del deber de aplicar la Constitución mexicana cuando ésta prevea una restricción expresa a un derecho humano.

En el engrose de la Contradicción de tesis 293/2011 (en adelante CT) se lee desde las páginas iniciales que "la nueva conformación del catálogo de derechos humanos no puede ser estudiada en términos de jerarquía", y "que los derechos humanos reconocidos en los tratados internacionales y en la Constitución no se relacionan entre sí en términos jerárquicos", ya que escapan "a la regulación de la jerarquía de las fuentes prevista en el artículo 133 constitucional". ${ }^{15}$ Sin embargo, poco después se precisa que aun si "los derechos humanos reconocidos en tratados internacionales se han integrado expresamente a nuestro ordenamiento jurídico interno, para ampliar el catálogo constitucional de derechos humanos", en virtud "de la parte final del primer párrafo del propio artículo $1^{\circ}$ constitucional, cuando en la Constitución haya una restricción expresa al ejercicio de los derechos humanos, se deberá estar a lo que indica la norma constitucional". ${ }^{16}$

Aunque haya sido por razones distintas, varios ministros y parte de la doctrina han visto en la combinación de estas afirmaciones una contradicción o, por lo menos, algo inexacto. ${ }^{17}$ Esencialmente, éstos han sostenido que no puede afirmarse la ausencia de jerarquía y luego imponer la

\footnotetext{
15 CT, p. 30.

16 CT, p. 37.

17 No es aquí el momento de disertar sobre matices semánticos, pero una cosa es destacar la inexactitud (como lo hace la ministra Sánchez Cordero, véase nota 15) o el contrasentido que deriva de la combinación de tesis (como lo hace el ministro Aguilar Morales, véase nota 17), y otra es afirmar, como lo hace Ortega García, que "la sentencia encierra una contradicción lógica insuperable" (op. cit., p. 265) o tachar la sentencia de "auto-contradictoria" (ibidem, p. 281).
} 
aplicación de una fuente (la Constitución) sin importar lo que esto implique en términos de protección de derechos humanos. Los que dudan de la compatibilidad entre estas afirmaciones difieren, por así decirlo, sobre qué cuerno del dilema hay que derribar. El ministro Cossío, por ejemplo, se quedaría con la ausencia de jerarquía, ya que rechaza la tesis de la restricción constitucional; en cambio, el ministro Aguilar se quedaría con la aplicación de la restricción constitucional, pues rechaza la tesis de la ausencia de jerarquía.

En palabras del ministro Cossío:

Si el párrafo segundo del artículo $1^{\circ}$ dispone que a las personas se les dará en todo momento la protección más amplia en términos de lo que dispongan los derechos humanos de fuente constitucional o convencional, no puede establecerse la prevalencia de las normas constitucionales en los casos en que establezcan restricciones, sin admitir que con ello se incorpora expresamente un criterio de jerarquía constitucional. ${ }^{18}$

Por su parte, el ministro Aguilar sostiene que "no puede predicarse una falta de relación jerárquica entre las normas de derechos humanos previstas en tratados internacionales y los preceptos constitucionales, pues aun con la reforma constitucional sigue imperando la supremacía constitucional". De esto deriva, sin necesidad de ulteriores premisas, que "en caso de que en la Constitución se prevea una restricción a un derecho humano, deberá prevalecer lo establecido en el texto constitucional". ${ }^{19}$

El problema práctico termina siendo el de saber qué norma jurídica debe prevalecer entre una norma constitucional mexicana y una norma

18 Cossío Díaz, José Ramón, "Voto particular", CT, pp. 2 y 3. En el mismo sentido, véase también Sánchez Cordero, Olga, "Voto concurrente", CT, p. 10: "me resulta un tanto inexacto que se establezca lisa y llanamente que no exista una relación de jerarquía entre los derechos humanos de fuente internacional y la Constitución, y a la vez, se sostenga que al existir una restricción se deba estar a lo que establece la Constitución, puesto que esta última cuestión implica de suyo una relación de subordinación normativa".

19 Aguilar Morales, Luis María, "Voto particular", CT, p. 5. Véase también p. 7: "A mi juicio es un contrasentido afirmar que las normas de derechos humanos previstas en tratados internacionales y las establecidas en la Constitución Federal no se relacionan en términos jerárquicos, y luego decir que aun así prevalecen las restricciones establecidas en la Constitución. Coincido en que éstas últimas deben prevalecer, pero precisamente porque sí existe una relación jerárquica entre dichas normas, que deriva del principio de supremacía constitucional". En el mismo sentido, véase Franco González Salas, José Fernando, "Voto concurrente y particular", CT, p. 8. 
internacional (especialmente interamericana) cuando se identifique un conflicto normativo. Pero tal problema práctico no debe ser confundido con un problema teórico, o de alta dogmática, en donde lo que está en juego no es la prevalencia de una u otra norma en un caso concreto, sino las relaciones, por así decirlo, formales entre distintas fuentes. Todos los que hablan en serio de jerarquía entre normas constitucionales y normas internacionales están probablemente y tácitamente asumiendo una perspectiva monista, esto es, la idea según la cual sólo hay un sistema jurídico, dentro del cual cada norma está relacionada jerárquicamente con las demás (aunque dos normas puedan tener la misma jerarquía).

En lo que sigue me dedicaré a trazar todas las distinciones que me parecen pertinentes para dar cuenta de los argumentos esgrimidos por los ministros. La utilidad de tales distinciones se medirá a partir de su capacidad de disolver desacuerdos aparentes, o sentar las bases para un más claro posicionamiento, a la vez teórico y práctico.

Las distinciones propuestas corresponden, en su mayoría, a ciertas ambigüedades: algunas propias del artículo 1o. constitucional, y otras por parte del lenguaje utilizado por los ministros para aclarar el significado de tal artículo. Un primer grupo se refiere al concepto de jerarquía (II); un segundo se refiere a la noción de normas de derechos humanos (problemática en sus dos componentes, es decir, "normas" y "derechos humanos") (III), y un tercero, en fin, se refiere a las nociones de norma restrictiva y de interpretación pro persona (IV). Ninguna de las distinciones es quizá nueva, lo que es nuevo es el intento de desterrar los significados implícitos (u obscuros) en el texto constitucional o en los argumentos de los ministros, en particular por lo que se refiere a las relaciones entre sistemas normativos $(\mathrm{V})$. Lo que más me importa es destacar que por cada combinación de significados tendríamos probablemente tesis distintas, sobre las cuales, en un futuro, los ministros podrían volver a pronunciarse.

\section{JERARQUÍAS NORMATIVAS Y SUPREMACÍA CONSTITUCIONAL: FE T'AIME MOI NON PLUS}

Fe t'aime moi non plus (literalmente "Te amo yo tampoco") es el título de una célebre canción de Serge Gainsburg. La frase del título, que reproduce el intercambio entre dos amantes, es voluntariamente incorrecta, ya que las dos formas correctas serían "Te amo yo también" o "No te amo yo tampo- 
co". Una explicación posible de tal formulación incorrecta es que aunque se profieran las palabras "te amo", el otro amante le atribuye el significado contrario, esto es, "no te amo", y por lo tanto contesta "yo tampoco", lo que, dada tal interpretación, es una respuesta adecuada. En fin, sin abundar en la interpretación de este llamativo título, es útil recordar que algunos han visto en esta canción la celebración del sexo sin amor: durante el sexo sin amor pueden pronunciarse frases como "te amo", cuyo significado, sin embargo, como anteriormente señalamos, es tal que una respuesta adecuada puede ser "yo tampoco".

¿A qué correspondería, en el ámbito de la justicia constitucional, el sexo sin amor? Un buen candidato sería la mayoría sin acuerdo, o el punto resolutivo sin ratio decidendi. Los acuerdos acerca de la existencia (o ausencia) de jerarquía pueden ser deconstruidos (y reconstruidos) a partir de ciertas definiciones de los conceptos clave, a los cuales dedicaré esta sección. Es posible identificar tres momentos semánticamente delicados. El primero se refiere al significado de la "ausencia de jerarquía" entre normas de derechos humanos (1); el segundo hace referencia al significado de la "supremacía constitucional" (2), y el tercero se refiere a la ambigüedad del término "jerarquía" cuando no es acompañado del adjetivo "formal", lo que deja abierta la posibilidad de que se hable de jerarquías, en particular, en sentido axiológico y no formal (3).

\section{Ausencia de jerarquía formal}

La primera ambigüedad deriva de los dos sentidos que puede tener la afirmación que niega la existencia de una jerarquía formal entre normas de derechos humanos: en primer lugar, la ausencia de jerarquía significa que dos entidades tienen el mismo nivel jerárquico (por ejemplo, entre dos jefes de departamento, en una misma universidad, no existe jerarquía); pero, en segundo lugar, la ausencia de jerarquía puede significar que no existe relación alguna entre las dos entidades, y, por lo tanto, por definición no puede existir una relación jerárquica (como sería en el caso, pongamos, del rector de la universidad "A" y del jefe de un departamento de la universidad "B"). Los que afirman la existencia de una jerarquía, como ya he sugerido, tienden a asumir una teoría monista; en cambio, los que niegan la existencia de una jerarquía lo pueden hacer desde una perspectiva monista (en la medida en que se piensa que las fuentes o normas tendrían el 
mismo nivel jerárquico dentro de un mismo sistema) o desde una perspectiva pluralista (en la medida en que las fuentes o normas no pertenecerían al mismo sistema, y por ende no podrían relacionarse jerárquicamente, con independencia de la importancia que tengan).

Desde un punto de vista teórico, por lo tanto, la adopción de una perspectiva monista o pluralista puede cambiar radicalmente el sentido de la tesis sobre la ausencia de relaciones jerárquicas. En particular, la tesis sobre la ausencia de jerarquía formulada por un pluralista es perfectamente compatible con la tesis de la supremacía constitucional, mientras que la misma tesis defendida por un monista es, por lo menos, en este nivel de análisis, incompatible con la tesis de la supremacía constitucional. Preciso "en este nivel de análisis", porque, como resultará claro, una vez analizadas las demás complicaciones semánticas, las tesis mencionadas pueden volverse compatibles si se entienden "jerarquía", "supremacía" y/o "normas de derechos humanos" en otros sentidos.

\section{Supremacía constitucional}

A esta primera ambigüedad se añade algo que no es solamente una ambigüedad (esto es, una pluralidad de significados para una misma palabra o expresión verbal), sino también una inconstancia terminológica al momento de hablar de "jerarquía". Puede hablarse, en efecto, de supremacía de algo sobre algo. Es en este sentido que se interpreta el artículo 133 constitucional como si estableciera la "supremacía" de la Constitución. ${ }^{20}$ Sin embargo, el término "supremacía" es en sí mismo ambiguo, ya que la Real Academia Española ofrece dos definiciones del mismo: "supremacía" significa "grado supremo en cualquier línea", pero también "preeminencia, superioridad jerárquica". En el segundo sentido afirmar la supremacía de las normas constitucionales sobre las normas internacionales de derechos humanos significa señalar la existencia de una relación jerárquica. Pero en el primer sentido puede hablarse de supremacía de la Constitución mexicana sobre las normas internacionales de derechos humanos sin asumir la existencia de una relación jerárquica.

20 "En este sentido, la doctrina jurisprudencial vigente de esta Suprema Corte de Justicia de la Nación considera que el artículo 133 constitucional contiene diversas normas, dentro de las cuales destacan la que constituye el postulado principal del principio de supremacía constitucional y la que sienta los parámetros bajo los cuales se ha construido la jerarquía normativa del ordenamiento jurídico mexicano” (GT, p. 24). 
Para resumir: toda superioridad jerárquica es necesariamente supremacía, pero no toda supremacía es superioridad jerárquica. No sorprende, por lo tanto, que el eje de la decisión de la Corte fue replantear "el concepto de supremacía constitucional para dar cuenta de su operatividad a la luz de las reformas constitucionales, y en especial del nuevo artículo $1^{0}{ }^{\circ} .{ }^{21}$ Anticipando algo, puedo sugerir desde ahora que probablemente parte del desacuerdo entre los ministros depende de la no distinción (en general, esto es, sin referirse necesariamente a las normas o fuentes de derechos humanos) entre superioridad jerárquica y supremacía. En este sentido, si se hubiera distinguido, no existiría ninguna contradicción en afirmar la ausencia de relaciones jerárquicas, por un lado, y la supremacía constitucional, por el otro. La confusión, sin embargo, deriva del uso predominante del término "supremacía" para referirse a las relaciones jerárquicas, como las establecidas por el artículo $133 .{ }^{22}$

Para que este punto quede más claro, hay que formular con claridad las asunciones teóricas que dan sentido a la distinción entre supremacía y superioridad jerárquica. Desde una perspectiva pluralista es perfectamente sensato afirmar la ausencia de jerarquía y al mismo tiempo defender la supremacía constitucional. Desde una perspectiva monista, los términos son prima facie sinónimos, salvo introducir un matiz político-moral en la noción de supremacía o, dicho en otros términos, salvo distinguir entre jerarquía en sentido formal y jerarquía axiológica. Dos normas pueden tener la misma jerarquía formal, y al mismo tiempo una de ellas puede ser considerada, en virtud de un juicio de valor, superior a la otra.

La relevancia de las asunciones teóricas respecto del monismo o del pluralismo se vuelve central cuando se trata de atribuir sentido a afirmaciones como la siguiente: "el principio de supremacía constitucional... implica... que el resto de las normas jurídicas deben ser acordes a la misma, tanto en un sentido formal como material". ¿Qué significa "el resto de las normas jurídicas"? O, más precisamente, ¿a qué se refiere esta expresión? Según el monista, el resto de las normas jurídicas son todas las normas jurídicas nacionales, internacionales, etcétera. Para el pluralista, pue-

21 CT, p. 31.

22 La identificación es clara en Pardo Rebolledo, Jorge Mario, "Voto concurrente", CT, p. 7: "Así, en mi opinión el artículo $1^{\circ}$ de la Carta Magna refleja el principio de supremacía constitucional que conlleva implícito el principio de jerarquía normativa".

23 CT, p. 47. 
de significar, sensatamente, las normas jurídicas que pertenecen al mismo sistema, pero no las que pertenecen a otros sistemas. Tintes monistas parecen vislumbrarse en la postura del ministro Aguilar Morales, cuando afirma que "de la Constitución deriva todo el marco normativo, incluso, desde luego, los tratados internacionales, incluyendo los de derechos humanos". ${ }^{24}$ Se trata, según me parece, de una postura perfectamente coherente si se asume el monismo con primacía estatal; esto es, la idea según la cual todas las normas jurídicas son tales en la medida en que directa o indirectamente derivan su validez de la Constitución nacional. Desde esta perspectiva, como ya lo hemos señalado, resulta incomprensible afirmar la ausencia de jerarquía entre normas de derechos humanos internacionales y normas constitucionales, ya que las primeras derivarían su validez de las segundas, y en tal caso no pueden considerarse jerárquicamente equivalentes. Esta insensatez, sin embargo, desaparece de dos formas: distinguiendo entre conceptos de jerarquías (formales y axiológicas) o diferenciando con claridad entre lo que se pretende jerarquizar: fuentes o normas. ${ }^{25}$

\section{Ferarquías axiológicas: democracia vs. humanidad}

La tercera ambigüedad es la siguiente: cuando se habla de "jerarquía", sin especificar que se trata de jerarquía formal, ${ }^{26}$ podría entenderse por "jerarquía" una jerarquía axiológica; esto es, una jerarquía que depende del valor (político-moral) que se atribuye a dos normas potencialmente - $\mathrm{O}$ actualmente - en conflicto. ${ }^{27}$ Ciertas normas a las cuales muy a menudo

24 Aguilar Morales, Luis María, op. cit., p. 3. En el mismo sentido, véase Franco González Salas, José Fernando, op. cit., pp. 5 y 6: "el primer y fundamental referente del juez constitucional mexicano al realizar juicios de constitucionalidad e, inclusive, de convencionalidad, en términos de la reforma del 10 de junio de 2011, debe ser nuestra propia Constitución".

25 Todo el razonamiento del ministro Zaldívar se basa sobre la distinción, elaborada por la doctrina italiana, entre disposición jurídica (un enunciado que pertenece a un texto normativo, como un tratado internacional) y norma jurídica (el contenido normativo o significado normativo atribuido a una disposición jurídica). Sobre esta distinción, la literatura es inmensa, pero es suficiente remitir a la excelente compilación que el mismo ministro se refiere: Pozzolo, Susana y Escudero, Rafael (eds.), Disposición vs. norma, Lima, Palestra, 2011. Volveré sobre las implicaciones de tal distinción en la conclusión de este trabajo.

26 En algunos casos se especifica (por ejemplo, CT, p. 24).

27 En palabras de Guastini, Riccardo, "Interpretación y construcción jurídica", Isonomía, núm. 43, 2015, en prensa: "Una jerarquía axiológica es una relación de valor entre 
se refiere la Corte Interamericana usando la expresión ius cogens (o normas inderogables) serían normas que a pesar de no tener mayor jerarquía formal, tendrían más valor, lo que las hace inderogables. ${ }^{28}$

Si se toma en cuenta esta distinción, puede afirmarse lo siguiente: no existe una jerarquía formal entre normas de derechos humanos constitucionales o internacionales, pero ciertas normas tienen mayor valor. No se trataría, en el caso de la CT, de invocar el carácter inderogable de ciertas normas de derechos humanos, en virtud de su intangible valor moral, sino quizá de invocar el carácter políticamente superior de las normas expresamente introducidas en el texto constitucional por el legítimo representante de la nación mexicana, a pesar de que éstas, por lo menos prima facie, restrinjan y no amplíen el ámbito de aplicación de las normas de derechos humanos. Se trataría de una aplicación banal del conocido argumento democrático: en caso de duda, o de conflicto entre normas, habrá de preferirse aquella que manifiestamente fue introducida por una voluntad democrática.

Si lo anterior es plausible, puede distinguirse entre dos tipos de jerarquía axiológica: una jerarquía de carácter esencialmente moral, y otra de carácter esencialmente político. El verdadero problema surgiría cuando se presentara un conflicto entre una norma protectora internacional con carácter de ius cogens ${ }^{29}$ y una norma constitucional restrictiva del ámbito de aplicación de la primera norma. Un caso paradigmático sería el siguiente: por un lado, la norma internacional que prohíbe la tortura (o que establece el derecho humano de no ser objeto de tortura), que por lo general se considera como norma de ius cogens, y por otro lado, una norma constitu-

normas, creada no por el propio derecho (como, por ejemplo, la jerarquía de las fuentes) sino por los intérpretes, por medio de un juicio de valor comparativo, expreso o tácito: «La norma N1 tiene más valor que la norma N2»".

28 Corte IDH, Caso Barrios Altos vs. Perú. Fondo. Sentencia del 14 de marzo de 2001, Serie C, No. 75, especialmente el voto concurrente del juez Antonio Cançado Trindade. Sobre una interpretación de la noción de ius cogens en términos de jerarquías axiológicas, véase Garibian, Sévane y Puppo, Alberto, "Acerca de la existencia del ius cogens internacional: una perspectiva analítica y positivista”, Isonomía, núm. 36, 2012, pp. 7-47, especialmente pp. $37-40$.

29 La primera utilización judicial de la noción de ius cogens fue la del Tribunal Penal para la ex Yugoslavia (TPIY Sala II, Anto Furundzja, 10 de diciembre de 1998, IT-95-17/1, $\S \S 153$ y ss.), que precisamente la aplicó a un caso de tortura. Para profundizar esta decisión fundadora, véase las referencias listadas en Garibian, Sévane y Puppo, Alberto, op. cit., p. 8. 
cional que autorice el uso de tortura en ciertos casos; por ejemplo, cuando una persona tenga información sobre un posible atentado terrorista que podría causar miles de muertes. Si la mayoría de los mexicanos, a través de sus representantes, hubieran decidido introducir una excepción a la prohibición de la tortura, no resulta prima facie completamente ilegítimo que se respete su voluntad, aunque respetar tal voluntad implique violar la prohibición de la tortura. Tampoco resulta ilegítimo pensar que la voluntad de la mayoría encuentra ciertos límites que corresponden a lo que algunos autores han llamado "la esfera de lo indecidible". ${ }^{30}$

Pero, sobre todo, resulta algo extraño pensar que un caso de este tipo pudiera realmente darse. Esta última observación no tiene que ver con cuestiones teóricas o normativas, sino con el sentido común. A la luz de este sentido común, en virtud del cual el caso paradigmático planteado resulta poco probable, hay que leer las agudas observaciones del ministro Gutiérrez Ortiz Mena: ${ }^{31}$

Las restricciones no habrán de aplicarse como reglas sujetas a subsunción, sino como elementos normativos que deberán interpretarse de manera conforme con los derechos humanos y, en su caso, se sujetarán al estándar de su compatibilidad con el sistema general de derechos humanos, ya que una abierta incompatibilidad de la restricción podría generar su inaplicación al trascender en el ámbito de lo indecidible (de ahí que sea una ponderación deferencial solamente).

El ministro distingue entre casos centrales y casos periféricos. Mi caso imaginario sería un caso periférico - una constitucionalización de violaciones de derechos humanos-, que merecería un "estándar distinto" y no el estándar establecido en la CT. ${ }^{32}$ Volveré más adelante sobre el

30 El ministro Gutiérrez Ortiz Mena destaca el carácter intangible de los derechos humanos cuando se refiere a la "indisponibilidad o supremacía de los derechos humanos" (op. cit., p. 3). Sobre la indisponibilidad de los derechos y la indecidibilidad de ciertas cuestiones, véase Ferrajoli, Luigi, "La esfera de lo indecidible y la división de poderes", trad. de Miguel Carbonell, Estudios Constitucionales, vol. 6, núm. 1, 2008, pp. 337-343, disponible en: wrere.cecoch.cl/docs/pdf/revista_ano6_1/Laesfera17.pdf. A esta obra hace expresamente referencia el ministro Zaldívar en su voto (Zaldívar Lelo de Larrea, Arturo, "Voto aclaratorio y concurrente", CT, p. XIV, nota 61).

31 Gutiérrez Ortiz Mena, Alfredo, "Voto concurrente", GT, p. 9.

32 Ibidem, pp. 9 y 10. Otro caso periférico podría ser el caso de una condena por parte de la Corte Interamericana. En este sentido, véase Silva García, Fernando, op. cit., p. 264: 
significado de las restricciones constitucionales; por el momento, sólo importa destacar que la supremacía de una norma puede derivar no de su jerarquía formal sino de su valor, ya sea político o moral. De existir un conflicto - como el planteado- entre una norma con mayor rango moral y otra norma con mayor rango político, esto es, entre una norma que mejor protege la humanidad y otra norma que mejor refleja la voluntad democrática, sólo podrá resolverse sobre la base de una decisión genuinamente política. El caso Gelman ${ }^{33}$ ofrece un buen ejemplo de ello, ya que se enfrentaron, por un lado, una decisión claramente democrática y, por el otro, ciertos valores morales que, por lo menos en opinión de la Corte Interamericana, son inviolables (y que la decisión democrática nacional manifiestamente estaba violando). ${ }^{34}$

A las ambigüedades que afectan el término "jerarquía" deben aunarse las que perjudican las entidades de las cuales se cuestionan las relaciones jerárquicas. Para utilizar la metáfora kelseniana de la pirámide de normas, podríamos decir que la cuestión de los escalones en la CT parece depender de conceptos cuyas propiedades definitorias, en lugar de tener la solidez de los escalones de una pirámide, se parecen más a unas dunas, cuya existencia misma y cuyas relaciones mutuas dependen en definitiva de la dirección del viento. Si las piezas para armar, en el juego de la jerarquía, no son sólidas, cualquier acuerdo al respecto tendrá la estabilidad de -y orientará como- una duna. ${ }^{35}$

\footnotetext{
“excepcionalmente el juez nacional podría desaplicar una restricción constitucional expresa ante la existencia de una sentencia condenatoria de la Corte IDH contra el Estado mexicano que declare la inconvencionalidad de dicha restricción constitucional expresa". No comparto esta idea, sobre todo si se piensa en el caso Gelman, en donde a pesar de la condena por parte de la Corte, no me parece que la ponderación hecha por el Estado (imaginando que hubiera resultado en una norma constitucional) no pueda ser defendida.

33 Corte IDH, Caso Gelman vs. Uruguay. Fondo y Reparaciones. Sentencia del 24 de febrero de 2011 , Serie C, No. 221.

34 Sobre el caso Gelman, en particular, y la relación entre democracia y protección internacional de los derechos humanos, en general, véase Gargarella, Roberto, "La democracia frente a los crímenes masivos: una reflexión a la luz del caso Gelman", Revista Latinoamericana de Derecho Internacional, núm. 2, 2015, pp. 1-15, disponible en: http://wrer.revistaladi.com.ar/ numero2-gargarella/.

35 Destacan la inestabilidad de los criterios establecidos en la CT: Pou Giménez, Francisca, op. cit.; Silva García, Fernando, op. cit., p. 252.
} 


\section{FUENTES, NORMAS DE DEREGHOS HUMANOS \\ Y DERECHOS HUMANOS: ¿PIRÁMIDES DE ARENA?}

En la CT, al momento de definir la cuestión de la existencia o de la ausencia de una jerarquía normativa, se cruzan por lo menos tres planos: el de las fuentes de derechos humanos, el de las normas de derechos humanos y el de los derechos humanos efectivamente garantizados. A continuación intentaré aclarar en qué sentido las nociones de jerarquía y/o de supremacía, tal y como fueron definidas en la sección anterior, aplican en estos tres niveles, en particular a la luz de la distinción entre derechos humanos naturales y reales (1), y entre normas de derechos humanos y derechos humanos (2).

\section{Derechos humanos naturales vs. derechos humanos reales}

Los derechos humanos pueden ser analizados desde una perspectiva naturalista, según la cual los Estados se limitan a reconocer algo que preexiste (A), o desde una perspectiva realista, en donde el acento se pone sobre su protección efectiva $(\mathrm{B})$.

\section{A. La titularidad de los derechos humanos y la metáfora del catálogo}

¿Existe el derecho natural? ¿Los derechos humanos son derechos naturales? Aunque el clima aparentemente dominante en muchos contextos jurídicos arbola un credo positivista, cuando se pisa el terreno de los derechos humanos el derecho natural tiende a recobrar un rol central. Esto es evidente en algunos votos de los jueces de la Corte Interamericana, ${ }^{36}$ pero quizá implícito también en ciertas posturas judiciales nacionales, como la del ministro Gutiérrez Ortiz Mena, cuando afirma que la "existencia de los derechos humanos es independiente a cualquier diseño institucional", y que "si los derechos humanos se reconocen por su contenido, no puede supeditarse ese reconocimiento a la fuente formal del que deriven". ${ }^{37}$ Por lo tanto, cabe la sospecha de que los derechos reconocidos por la Cons-

\footnotetext{
36 Véase, paradigmáticamente, el voto del juez Cançado Trindade en el caso Barrios Altos, en donde se multiplican las referencias a la "conciencia jurídica de la humanidad" o a las "leyes de la humanidad". Corte IDH, Caso Barrios Altos vs. Perú, cit.

37 Gutiérrez Ortiz Mena, Alfredo, op. cit., pp. 3 y 5, respectivamente.
} 
titución y los tratados sean derechos naturales. Si así fuera, por supuesto no tendría ningún sentido imaginar un jerarquía entre derechos humanos naturales. Las dos fuentes (nacional e internacional) sólo tendrían valor "cognitivo". 38

Otro elemento semántico interesante es el uso de la palabra "catálogo" ${ }^{39}$ El catálogo no crea nada, sino simplemente cataloga algo que preexiste. Todos tenemos bien presente lo que es un catálogo de exposición, así como entendemos lo que es una colección de obras de arte. En un artículo reciente dedicado al pragmatismo conceptual, Giovanni Tuzet se plantea la siguiente pregunta: ¿tiene sentido coleccionar derechos fundamentales? ${ }^{40}$ Obviamente, el coleccionista de derechos humanos será muy orgulloso de su catálogo de derechos humanos, y sobre todo dirigirá una mirada condescendiente al humilde coleccionista de meras garantías procesales. No cabe duda que las garantías las establece el legislador, que provee a las personas de los medios para hacer valer sus pretensiones. El cambio de vocabulario operado por el artículo lo. constitucional permite enorgullecerse: ya somos titulares de un catálogo de derechos humanos; tal catálogo no puede menoscabarse ${ }^{41}$ y se ve ampliado por la inclusión de los derechos humanos reconocidos por los tratados internacionales. ${ }^{42} \mathrm{La}$ palabra "garantía" casi empezó a simbolizar una época pasada, una época obscura en donde la vida jurídica no recibía la iluminación celestial de los derechos humanos. Más allá de marcar un cambio de vocabulario, la distinción entre derechos y garantías es esencial para entender gran parte de los argumentos esgrimidos por los ministros.

38 En este sentido, véase Guastini, Riccardo, Le fonti del diritto. Fondamenti teorici, Milán, Giuffré, 2010, cap. X. Aquí se habla de "fuentes de cognición" para distinguirlas de las "fuentes de producción". Las primeras son herramientas para conocer un derecho que existe con independencia de ellas; en cambio, las segundas son actos normativos de producción jurídica, o sea, son constitutivas de normas.

39 La palabra "catálogo" se repite constantemente en el engrose. Véase CT, pp. 27-53. Quizá es más atinada el término "cúmulo" usado (¿lapsus freudiano?) una vez por Sánchez Cordero (op. cit., p. 21). En efecto, si el catálogo hace pensar a un criterio de ordenación, el cúmulo parece resultar de la mera acumulación (lo que normalmente es sinónimo de desorden).

40 Tuzet, Giovanni, "Una concepción pragmatista de los derechos", Isonomía, núm. 39, 2013, pp. 11-36.

41 CT, p. 50.

42 Ibidem, p. 37. 


\section{B. La garantía de los derechos humanos y el escepticismo hacia los derechos de papel}

Hace muchos años, el realismo jurídico, en particular norteamericano, había señalado la tendencia de ciertos juristas hacia el uso del vocabulario de los derechos, y había manifestado un gran escepticismo al respecto. Karl Llewellyn, en un texto publicado por primera vez en 1930 y revisado, a partir de una postura más madura, en 1962, distinguía con una claridad extrema entre intereses, derechos y garantías. ${ }^{43}$ Su tesis era que el derecho, en particular los jueces, protege intereses a través de las garantías que el derecho positivo ha establecido. En el caso de querer usar el vocabulario de los derechos - decisión inevitable dada la tendencia dominante-, Llewellyn llamó la atención sobre la necesidad de distinguir con fuerza entre los derechos de papel (paper rights) y los derechos reales (real rights), esto es, entre los catálogos de derechos y los derechos realmente garantizados por los jueces y otras autoridades. Tal distinción no es sino el corolario de una distinción más general: reglas (o normas) de papel y reglas (o normas) reales. ${ }^{44}$

Las normas de derechos humanos pueden, entonces, ser naturales, de papel o reales. Los derechos reales son, en definitiva, las viejas garantías, esto es, los derechos efectivamente protegidos por el Estado. Si se acepta la distinción, es posible afirmar, en cuanto a la jerarquía, o a su ausencia, entre normas de derechos humanos, las siguientes tesis: a) no existe jerarquía entre de derechos humanos naturales; b) puede existir jerarquía entre derechos humanos reales (garantías), y c) los derechos humanos de papel - textos constitucionales y convencionales - tienen la misma jerarquía, ya que sólo reconocen algo que preexiste: los derechos humanos naturales. ${ }^{45}$ Si se niega la existencia del derecho natural, quedarían dos tesis: a) no existe jerarquía entre derechos humanos de papel, pues sólo es un catálogo, y b) puede existir jerarquía entre derechos humanos reales (garantías).

43 Llewellyn, Karl N., "Una teoría del derecho realista: el siguiente paso", en Casanovas, Pompeu y Moreso, José Juan (eds.), El ámbito de lo jurídico, Barcelona, Crítica, 1994, pp. 244-293.

44 Ibidem, pp. 249-268.

45 Gutiérrez Ortiz Mena, Alfredo, op. cit., p. 4. Él señala, en el sentido indicado en el texto, que las dos fuentes son equivalentes. 
Todo lo anterior sufre, sin embargo, de una falta de distinción. En efecto, la Constitución habla no sólo de "derechos humanos reconocidos", sino también de "normas de derechos humanos", nociones que es necesario distinguir.

\section{Derechos como normas vs. derechos como posiciones normativas}

Hay que preguntarse cuál es la relación entre normas de derechos humanos y derechos humanos reconocidos/garantizados. La distinción puede reducirse a la diferenciación entre dos enunciados-tipo: el primero afirma la existencia de una norma jurídica, y el segundo señala la existencia de un derecho. La norma jurídica, contrariamente a la orden de un ladrón, existe si ha sido creada por una autoridad competente. La existencia de un derecho (subjetivo), en cambio, depende necesariamente de la existencia de una relación entre dos sujetos. ${ }^{46}$ La distinción es relevante, porque una vez identificadas las normas de derechos humanos, todavía no sabemos mucho sobre qué derechos tiene cada persona. ${ }^{47}$

La estructura general que refleja la relación entre normas y derechos es bastante sencilla. Las normas establecen ciertas consecuencias normativas o soluciones para ciertos casos, definidos por un conjunto de propiedades (las reglas), o para todos los casos (principios), ${ }^{48}$ mientras que los derechos son posiciones jurídicas que ciertos sujetos adquieren en virtud de ciertas normas. Por lo menos desde la obra de Alexy, ${ }^{49}$ los constitucionalistas tienden a pensar que existe una relación muy estrecha entre las normas de tipo principio y los derechos fundamentales. Pero no se trata de una identidad: un principio sigue siendo una norma, una prescripción; por su parte, un derecho es una posición normativa que un sujeto puede oponer

46 Sobre el aspecto relacional de los conceptos jurídicos, en general, y de los derechos subjetivos, en particular, véase, por todos, Hohfeld, W. N., Conceptos jurídicos fundamentales, 4a. ed., México, Fontamara, 1997, pp. 25-97.

47 Por lo tanto, es falso, o por lo menos ingenuo, afirmar que "los derechos de que goza una persona en México constituye un conjunto de normas relativas a los derechos humanos" (Labardini, Rodrigo, "El (inexistente) derecho humano más humano que otro", Boletín Mexicano de Derecho Comparado, núm. 139, enero-abril de 2014, p. 335). En lugar de "constituye" habría que decir "derivan de" o "son constituidos por".

48 Volveré sobre la distinción entre reglas y principios en la próxima sección.

49 Alexy, Robert, Teoría de los derechos fundamentales, Madrid, Centro de Estudios Políticos y Constitucionales, 2007, cap. 4. 
a otros, y a la cual corresponden otras posiciones normativas. Cuál es mi derecho depende de una cierta operación que se hace con los principios: en sentido amplio, se trata de interpretar las formulaciones constitucionales, y en sentido estricto - otra vez si se sigue al autor alemán-, se trata de ponderar los principios.

En pocas palabras: los derechos humanos que tenemos dependen de la conducta de los jueces, que a partir de un conjunto de normas "sobre derechos humanos" determinan las posiciones jurídicas de los distintos sujetos involucrados: ${ }^{50}$ primeramente in abstracto (como en el contexto de una acción de inconstitucionalidad), y luego in concreto (como en un juicio de amparo).

\section{REGLAS VS. PRINCIPIOS: LA AMBIGÜEDAD DE LAS RESTRICGIONES CONSTITUCIONALES}

La distinción entre reglas y principios se ha vuelto fundamental a la hora de dar cuenta del razonamiento de los jueces constitucionales. Tal distinción debe ser combinada con la diferencia entre conflictos in abstracto y conflictos in concreto, dado que los jueces constitucionales solucionan no sólo casos individuales, sino también casos genéricos, como en una acción de inconstitucionalidad (1). Todo lo anterior arrojará luz sobre el significado de las restricciones constitucionales expresas y su relevancia a la hora de identificar, y eventualmente solucionar, un conflicto entre normas constitucionales y normas internacionales de derechos humanos (2).

\section{Conflictos normativos: reglas vs. principios}

Antes de precisar en qué sentido se usa "norma" en el artículo 1 lo. constitucional, y replantear así la cuestión de los conflictos normativos y de las restricciones constitucionales - tema central en la CT-, debemos recordar que las normas han sido concebidas como condicionales, cuyo antecedente es un supuesto de hecho (un caso) y cuyo consecuente una

50 En este sentido, véase Raz, Joseph, La autoridad del derecho. Ensayos sobre derecho y moral, 2a. ed., México, UNAM, Instituto de Investigaciones Jurídicas, 1985, cap. 6, especialmente p. 141: "Los tribunales tienen facultades para pronunciar una determinación autoritativa de la situación jurídica de las personas". 
solución (o una sanción, según la conocida concepción kelseniana). ${ }^{51}$ Más allá de la estructura lógica de los enunciados normativos, el punto constante era que siempre había una conducta típica, definida por algunas propiedades, lo que Alchourrón y Bulygin llamaron "propiedades del universo de casos". ${ }^{52} \mathrm{El}$ antecedente de la norma "kelseniana" es el caso, definido por un conjunto de propiedades. Un conflicto normativo se da cuando el sistema jurídico imputa al mismo caso dos consecuencias normativas tales, donde la observancia de una norma implica la inobservancia de la otra. ${ }^{53}$

Usando la terminología contemporánea, puede afirmarse sin hesitación que Kelsen, Alchourrón y Bulygin tenían en mente reglas. En efecto, por lo menos a partir de la obra de Dworkin y de Alexy, ${ }^{54}$ los juristas tienden a considerar que dentro de la categoría más general de "norma" hay que distinguir entre reglas (las normas kelsenianas) y principios. Los principios se distinguen por limitarse a afirmar una consecuencia jurídica de forma categórica o, dicho en términos más sofisticados, se distinguen por no tener condiciones explícitas de aplicación. Por esta razón, los expertos en principios tienden a afirmar que cuando dos principios entran en colisión, el jurista (in abstracto) o el juez (in concreto) deben explicitar las condiciones de la precedencia que se atribuye a uno de ellos. La formulación de las condiciones de aplicación de la consecuencia normativa establecida por el principio no es sino la formulación de una (nueva) regla, aunque no de nuevo derecho (ya que la regla estaba, de alguna forma, implícita en los principios). ${ }^{55}$

La distinción entre reglas y principios debe ser combinada con la diferencia entre disposiciones y normas. Esto puede arrojar luz sobre lo que los ministros afirman acerca de los conflictos entre normas constitucionales e internacionales de derechos humanos, y en particular sobre el papel

51 Por todos, véanse Kelsen, Hans, Teoría pura..., cit.; Alchourrón, Carlos E. y Bulygin, Eugenio, Introducción a la metodología de las ciencias jurídicas y sociales, Buenos Aires, Astrea, 1974 .

52 Alchourrón, Carlos E. y Bulygin, Eugenio, op. cit.

53 Kelsen, Hans, "Derecho y lógica", op. cit., p. 275: "Un conflicto de normas [es] una situación en la cual dos normas son válidas y de las cuales una prescribe una conducta específica y la otra prescribe una conducta incompatible con la primera".

54 Véase, por lo menos, Dworkin, Ronald, Taking Rights Seriously, Cambridge, Harvard University Press, 1978; Alexy, Robert, op. cit., cap. 5.

55 Sobre la explicitación de las condiciones de precedencia de un principio, véase Alexy, Robert, op. cit., pp. 91 y ss. En cuanto a la construcción de normas implícitas, véase Guastini, Riccardo, "Interpretación y construcción jurídica", op. cit. 
que juegan las restricciones constitucionales. Si los conflictos entre reglas, kelsenianamente, son tradicionalmente resueltos a partir de la jerarquía distinta entre las reglas en conflicto, o por medio de una norma que explícitamente deroga a una de las reglas en conflicto, o, en fin, en virtud de una decisión judicial que anula una de las reglas en conflicto, los conflictos entre principios parecen escapar a la elaboración teórica kelseniana, y en particular a la aplicación de los métodos tradicionales de resolución de los conflictos normativos. Para Alexy, es claro que cuando dos principios entran en conflicto, a pesar de que uno de los dos no pueda aplicarse, ninguno de los dos sale de la batalla perdiendo su validez. ${ }^{56}$

En efecto, los principios no son ni válidos ni inválidos, sino más bien criterios de validez para otras normas. En ningún caso una colisión entre principios se resuelve por la invalidación de uno de ellos; por tal motivo, resulta inaplicable cualquier razonamiento en términos de jerarquía formal. ${ }^{57}$ En caso de aceptarse este planteamiento, la consecuencia práctica, si aplicamos la teoría a la postura de la SCJN, sería la siguiente: no hay jerarquía entre normas de derechos humanos constitucionales e internacionales, porque no se da jerarquía formal entre principios. Lo único que se tendría sería un conjunto de criterios de preferencia o, en sentido amplio, interpretativos, tal como el de interpretación conforme, el pro persona o el pro-restricción expresa. ${ }^{58}$ La preferencia para la interpretación conforme parece situarse en un nivel superior, ya que en cualquier caso parece no haber razones para no buscar una interpretación de todas las fuentes prima facie aplicables para que las normas expresadas no resulten en conflicto. Este último enunciado tiene, sin embargo, dos significados, dependiendo de si se consideran las normas de derechos humanos o los (efectos reales de los) derechos humanos. Esta diferencia permite trazar la distinción entre conflictos in abstracto y conflictos in concreto.

\footnotetext{
56 Alexy, Robert, op. cit., p. 89.

57 El ministro que pone más énfasis en la distinción entre reglas y principios, por un lado, y relaciona la ausencia de jerarquía formal con la naturaleza de principio de las normas de derechos humanos, por el otro, es Gutiérrez Ortiz Mena (op. cit., pp. 6 y 7). Como ya hemos visto, que no exista jerarquía formal no significa que no haya jerarquía axiológica.

58 Tomo la expresión "pro-restricción expresa" de Pou Giménez, quien pone atinadamente sobre el mismo plano los criterios pro persona y pro-restricción expresa. Pou Giménez, Francisca, op. cit.
} 
In abstracto puede darse un conflicto entre principios; por ejemplo, la libertad de expresión y el derecho a la vida privada. Pero nadie está realmente interesado en conflictos de este tipo. Hay que distinguir, por tanto, dos categorías de conflictos in abstracto. Puede darse un conflicto in abstracto entre dos principios (constitucionales y/o convencionales) o un conflicto in abstracto entre una regla legislativa y un principio (constitucional y/o convencional). El control abstracto de constitucionalidad tiene que ver con un conflicto abstracto del segundo tipo. Aunque sea abstracto en el sentido en que no existe un caso concreto para el cual buscar una solución, no es tan abstracto, ya que dada la formulación de la regla legislativa cuestionada, el juzgador puede imaginarse el caso concreto que actualizaría el conflicto. Cuando analiza una regla, el juzgador tiene preconfeccionado lo que se conoce como "caso genérico", aunque no exista sobre la mesa un caso concreto. Así, en un conflicto puro entre principios falta el caso genérico, ya que - como hemos visto - el caso genérico se define a partir de un conjunto de propiedades que, en el caso de los principios, no son explícitas.

Cuando el conflicto es in concreto, los jueces se enfrentan a una pregunta: ¿es o no el caso concreto una instanciación del supuesto de hecho de una regla jurídica aplicable (esto es, del caso genérico)? Aquí también hay que distinguir varias situaciones. En primer lugar, debemos preguntarnos si existe o no una regla que expresamente regule el caso concreto. Si no existe tal regla, la solución dependerá de una ponderación entre principios, cuya conclusión será la formulación de una regla aplicable al caso. En tal caso se aplicarán sin dudas y sin mayores dificultades los principios de interpretación conforme y pro persona. Pero cuando una regla parece regular el caso, la situación es mucho más compleja. Si la regla es legislativa, habrá que preguntarse si la regla respeta los derechos humanos, a partir del parámetro integrado de regularidad constitucional (constitucional-convencional). Allí jugará el principio de interpretación conforme, sobre todo para interpretar la disposición legislativa — si es posible-, de tal forma que no viole el parámetro constitucional de validez. Al mismo tiempo, el parámetro constitucional se construirá tomando en cuenta no sólo la exigencia de armonización propia de la interpretación conforme, sino también la dirección de ajuste pro persona.

El caso realmente difícil, que inevitablemente dividió a los ministros, es el caso de una regla restrictiva constitucional. 


\section{Restricciones de derechos pro persona: ¿isabiduría democrática?}

Hasta ahora se ha asumido una distinción bastante pacífica entre reglas y principios, en donde los principios son expresados por fuentes constitucionales o convencionales, y las reglas, por fuentes subconstitucionales, como las leyes. La Constitución mexicana, sin embargo, tiene una característica que obliga a complicar el cuadro; en efecto, incluye disposiciones que parecen expresar reglas, las cuales, por lo tanto, pueden potencialmente dar lugar a un caso de conflicto con un principio, ya sea constitucional o convencional. Tal es el caso de una regla que restrinja el goce de un derecho reconocido por la Constitución o un tratado internacional.

La postura de varios ministros - como hemos visto - fue que la tesis según la cual si existe una restricción constitucional expresa, ésta habrá de aplicarse, contradice la tesis que establece la ausencia de jerarquía entre normas de derechos humanos constitucionales y convencionales, y sobre todo va en contra del principio pro persona, consagrado por el mismo artículo 1o. constitucional. Hay que recordar la formulación constitucional: "Las normas relativas a los derechos humanos se interpretarán de conformidad con esta Constitución y con los tratados internacionales de la materia favoreciendo en todo tiempo a las personas la protección más amplia". En esta disposición se hace referencia, potencialmente, a los tres niveles que he tratado de distinguir. Cuando se habla de "normas relativas a los derechos humanos" y de su interpretación pueden entenderse cosas bien distintas, dependiendo de qué conceptos de interpretación y de norma se adopten (A), con consecuencias importantes sobre el carácter potencialmente excluyente (de toda ponderación) que tendrían las restricciones expresas (B). Cualquier conclusión, que podría tener tintes dramáticos para ciertos defensores de los derechos humanos, debe ser matizada, ya que en la medida en que los derechos y los deberes van de la mano, en un sentido por lo menos, toda restricción es también protección $(\mathrm{C})$.

\section{A. La aplicación del principio pro persona: normas vs. disposiciones}

En la medida en que la CT parece asumir la distinción entre disposición y norma, habría que concluir que lo que se interpreta son las disposiciones y que, precisamente, el resultado de la interpretación es la formulación de una norma. Un enunciado interpretativo tendría la siguiente 
forma: "D significa N". Dada la ambigüedad del lenguaje, un enunciado interpretativo tendrá posiblemente la siguiente forma: "D significa N1, o N2, o N3, etcétera".

Si se toma en serio la relación entre disposiciones, normas e interpretación, habría que entender la referencia, dentro del artículo lo., a las normas relativas a derechos humanos como una alusión al significado de "disposiciones relativas a derechos humanos" o "normas de papel" (en el sentido anteriormente precisado). Por otro lado, al referirse a la "protección" de la persona parecería que se esté entendiendo algo parecido a las normas reales, o efectos reales (las posiciones jurídicas resultantes) de las normas de derechos humanos, esto es, las garantías de los derechos humanos.

Si se acepta lo anterior, la Constitución podría leerse de la siguiente forma: las disposiciones jurídicas (esto es, los textos) relativas a derechos humanos deben ser interpretadas de tal forma que la aplicación de las normas así obtenidas se traduzcan, en cada caso concreto, por la protección más amplia de los derechos de las personas involucradas. Por ejemplo, puede resultar que entre N1 y N2, cuando sean aplicadas a un caso concreto, $\mathrm{N} 1$ resulte ampliar la protección de una persona. Si, en cambio, se toma la referencia a las normas (y no a los textos o a las disposiciones jurídicas) en sentido estricto, el texto constitucional puede, igualmente, tener sentido, siempre y cuando se acepte la distinción entre interpretación in abstracto e interpretación in concreto. Hablando de normas, el constituyente estaría refiriéndose al resultado de una interpretación in abstracto, esto es, a la atribución de significado a ciertos textos (incluyendo textos que no son relativos a derechos humanos, y que, sin embargo, pueden, una vez interpretados, expresar normas relativas a derechos humanos). Una norma, a pesar de ser el resultado de una actividad interpretativa, sigue siendo un enunciado, lo cual hace inteligible la exigencia de interpretarla de tal o cual forma. La norma obtenida a partir de una interpretación in abstracto deberá ser interpretada, en cada caso concreto, de la forma que brinde a las personas la protección más amplia.

Aunque a primera vista las dos interpretaciones parecen equivalentes, existe una diferencia importante. En el segundo caso se estaría incluyendo en lo que debe interpretarse pro persona, el conjunto de normas que restringen los derechos. En efecto, una disposición jurídica que autoriza, por ejemplo, el arraigo no es una disposición relativa a derechos humanos, pero la norma expresada por ella es manifiestamente una norma restricti- 
Esta revista forma parte del acervo de la Biblioteca Jurídica Virtual del Instituto de Investigaciones Jurídicas de la UNAM

va de algún derecho humano, y por lo tanto relativa a derechos humanos. Se debe analizar, entonces, las consecuencias, en términos de restricciones constitucionales, de las dos lecturas.

\section{B. Restricciones excluyentes vs. restricciones ponderables}

En el primer caso, la disposición cuyo sentido es una restricción de un derecho no entra en el juego interpretativo. El juego interpretativo sólo se aplica a las disposiciones prima facie protectoras. Dada una norma (entre N1, N2 y N3) más protectora (pongamos N1), podría ser que ésta entre conflicto con una norma constitucional restrictiva (NR) del derecho protegido por N1. Según lo establecido por la CT, el parámetro de constitucionalidad debería ser, por lo tanto, NR y no N1. Así se resolvió, a mi parecer, el caso del arraigo. ${ }^{59}$ Dada la disposición constitucional que autoriza el arraigo, se consideró que la legislación federal debía controlarse a la luz de la norma expresada por el artículo constitucional pertinente, lo que - por ejemplo - llevó al ministro Aguilar Morales a la conclusión de que la legislación federal era inconstitucional, no por violar normas de derechos humanos, sino por ir más allá de la competencia establecida en el texto constitucional, que - hay que recordarlo - se refiere a la delincuencia organizada y no a la categoría más amplia de los delitos graves. ${ }^{60}$

En el segundo caso, por su parte, los textos cuyo significado es una restricción de derechos humanos entran en el proceso interpretativo, cuya dirección de ajuste es la protección más amplia de la persona. Antes de la $\mathrm{CT}^{61}$ podía entenderse que todas las normas, protectoras y restrictivas, en-

59 ADR 1250/2012, disponible en: http://wrew2.scjn.gob.mx/ConsultaTematica/Paginas Pub/DetallePub.aspx?AsuntoID $=138663$.

60 ADR 1250/2012, Versión taquigráfica de la sesión del 14 de abril de 2015, p. 28, disponible en: https://wrere.scjn.gob.mx/PLENO/ver_taquigraficas/14042015PO.pdf: "Considero que si bien el arraigo está en la Constitución sólo se puede hacer en materia de delincuencia organizada y no como lo hizo el Congreso de la Unión para delitos graves cuando está partiendo de una cláusula habilitante que no es tal el artículo décimo primero transitorio. Y desde este punto de vista considero que es inconstitucional".

61 El ejemplo paradigmático es la AC 155/2007, en donde se interpretó la Constitución a la luz de los tratados, de tal forma que se ampliara la libertad de trabajo, y, por consiguiente, se declaró inconstitucional una legislación estatal que autorizaba sanciones administrativas consistentes en trabajos comunitarios. Todo ello, a pesar de que existiera una restricción constitucional expresa (formulada en el artículo 21) de la libertad de tra- 
traban en juego con las mismas armas, y que en caso de no encontrar una interpretación armónica de todas, se tendría que haber preferido el resultado que brindara la protección más amplia. Pero ahora parecería que sólo la norma restrictiva tiene (más) derecho de pretender su aplicación, que su existencia puede excluir la relevancia de las normas protectoras, aunque su aplicación deba o pueda obedecer a la interpretación más restrictiva de la restricción, lo que se traduce como una protección más amplia de los derechos de la persona. ${ }^{62}$ Más amplia, por supuesto, dada la existencia de la norma restrictiva, ya que, obviamente, en términos absolutos, la más amplia sería consecuencia de la no aplicación de la restricción.

Como ha pasado muy a menudo en momentos anteriores de mi argumentación, aquí también es necesario hacer una pausa y dar un paso atrás. En efecto, hasta ahora se ha adoptado una visión ingenua de las dos nociones clave: restricción y protección. Un atento lector debería, en efecto, haber tenido una reacción hostil leyendo los párrafos anteriores y merece una aclaración.

\section{Derechos vs. deberes humanos: las restricciones bajo su mejor luz}

No puede negarse que cualquier derecho atribuido a una persona por una regla tiene aparejado el deber (y el no derecho) correspondiente de otra persona, ${ }^{63}$ y que cualquier derecho atribuido por un principio tiende inexorablemente a entrar en colisión con otros derechos atribuidos por otros principios.

bajo que habría podido invocarse para defender la constitucionalidad de la legislación en cuestión.

62 En el sentido de una interpretación restrictiva de las restricciones, véanse, entre otros, Gutiérrez Ortiz Mena, Alfredo, op. cit.; Zaldívar Lelo de Larrea, Arturo, op. cit., p. XXI, en donde sugiere "interpretar las restricciones expresas al ejercicio de los derechos humanos de forma restrictiva, maximizándose el ámbito protector del derecho humano en cuestión".

63 La noción de no derecho ha sido introducida y definida por Hohfeld (Hohfeld, W. N., op. cit.). Franco González Salas cita atinadamente el capítulo V del Pacto de San José, cuyo título es "Deberes de las personas" (Franco González Salas, José Fernando, op. cit., p. 12). El artículo 32, denominado "Correlación entre derechos y deberes", segundo párrafo, afirma: "Los derechos de cada persona están limitados por los derechos de los demás, por la seguridad de todos y por las justas exigencias del bien común, en una sociedad democrática". Zaldívar Lelo de Larrea afirma explícitamente que, por lo menos en ciertos casos, "la restricción protege derechos humanos de terceros o garantiza la igualdad material entre las personas" (Zaldívar Lelo de Larrea, Arturo, op. cit., p. XVI). 
Lo anterior apunta a destacar que algunas normas constitucionales restrictivas son reglas que reflejan el resultado de una ponderación entre principios en conflicto operada por el legislador. Tales reglas han sido formuladas, como hemos visto al analizar la distinción entre principios y reglas, a partir de un balance de razones que son, potencialmente, todas pro persona. El resultado del balance aparecerá restrictivo desde un punto de vista, pero protector desde otro $(a)$. Dije "potencialmente", pues no es imposible que el balance se base en una ponderación que se considere inadecuada; por ejemplo, porque se considera el sacrificio casi total de un determinado valor como injustificado. Sería el caso de lo que el ministro Gutiérrez Ortiz Mena ha llamado una "constitucionalización de la violación de un derecho humano", ${ }^{64}$ esto es, la restricción de un derecho a la cual no corresponde la protección de otro derecho, un caso de "arbitrariedad o exceso de las autoridades" (b). ${ }^{65}$

\section{a. Restricciones protectoras}

Hay que tomar un ejemplo muy sencillo, casi banal: la aplicación de una regla que obliga a reparar el daño causado por la publicación de una foto no autorizada es pro persona si se adopta el punto de vista de la persona objeto de la foto, pero no es pro persona, es decir, restrictiva, si se adopta el punto de vista del fotógrafo.

Este ejemplo sugiere una distinción. Tal aplicación favorable a la persona objeto de la foto, víctima de una afectación de su vida privada, podría resultar de tres situaciones normativas distintas: (a) una regla constitucional que establezca claramente, para el caso de una "publicación de foto sin autorización", el deber de reparar el daño; (b) un principio que proclame la libertad de expresión dentro de los límites inherentes al respeto a la vida privada, y (c) dos formulaciones, potencialmente sin límites, del derecho a la libertad de expresión y del derecho al respeto de la vida privada. En (a) se trataría de una regla restrictiva de la libertad de expresión, y en (b), de un límite a su ejercicio; por su parte, en (c) no podríamos hablar, en sentido estricto, de una restricción o de una limitación de un derecho, ya que la limitación no derivaría de un texto, sino de la inevitable colisión, en un caso concreto, entre los dos principios.

64 Gutiérrez Ortiz Mena, Alfredo, op. cit., p. 5.

65 Franco González Salas, José Fernando, op. cit., p. 14. 
Retomando las posibles interpretaciones del artículo 1o. constitucional, en (a) no se trataría de una disposición jurídica relativa a los derechos humanos, pues sólo se trataría de establecer un caso de responsabilidad civil; en (b) se haría referencia, en cambio, a una disposición relativa a derechos humanos, ya que su objeto principal sería el reconocimiento de la libertad de expresión, y la restricción vendría como límite al ejercicio de la misma; finalmente, en (c) no se trataría de una restricción constitucional, aunque la restricción inevitablemente sea la consecuencia del carácter no absoluto de todos los derechos. ${ }^{66}$ Los tres casos se distinguen también por el grado de discrecionalidad que el legislador constitucional ha decidido dejar a los jueces. En (a) los jueces deberían aplicar la consecuencia jurídica establecida por el precepto constitucional; en (b) ellos tendrían que valorar si la publicación de una foto sin autorización, en un caso concreto, constituye un caso de violación de la vida privada no amparada por la libertad de expresión, y en (c) aquéllos deberían ponderar los dos principios, llegando a una conclusión, potencialmente, más favorable al fotógrafo y más restrictiva del derecho a la vida privada.

Para entender la dinámica de las restricciones y la relevancia de la CT al respecto, necesitamos imaginar un caso algo complejo. ¿Cuál sería la diferencia entre la primera hipótesis (regla constitucional que restringe la libertad de expresión en virtud de la prohibición de publicar fotos no autorizadas) y la tercera hipótesis (ausencia de reglas constitucionales) complementada por una regla legislativa cuyo contenido fuera idéntico al de la regla constitucional del primer caso? Imaginando que el sentido de la ponderación fuera el que he imaginado, esto es, una ponderación favorable a los derechos de los fotógrafos, la diferencia es de una importancia capital. A pesar de estar en desacuerdo con la ponderación efectuada por el legislador constitucional, los jueces, en el primer caso, deberían aplicar la restricción constitucional y dejar sin protección al fotógrafo. En el segundo caso, en cambio, ellos podrían declarar inconstitucional la regla legislativa que restringe excesivamente la libertad de expresión. Lo que quiero subrayar es que, en todo caso, se estaría, en definitiva, brindando

66 Muchos ministros han destacado la relevancia del carácter no absoluto de los derechos al momento de atribuir sentido a la tesis de las restricciones constitucionales. Por todos véanse Sánchez Cordero, Olga, op. cit., pp. 12-18; Gutiérrez Ortiz Mena, Alfredo, op. cit., pp. 6-1 1; Zaldívar Lelo de Larrea, Arturo, op. cit., p. XII, que perentoriamente afirma: "resulta pacífico sostener que los derechos humanos no son absolutos". 
la protección más amplia; sin embargo, la diferencia consiste en qué la persona que merece la protección cambia según se trate del legislador o del juez.

Ahora hay que plantear el caso de una restricción constitucional expresa que no tenga una contrapartida "protectora".

\section{b. Restricciones no protectoras: casos claros y casos dudosos}

Un caso claro sería el relativo a la autorización de la tortura para luchar en contra de la delincuencia organizada. Por importante que sea tal lucha, resulta difícil ver qué derechos podrían estar protegidos en los casos de tortura. En este caso, atendiendo a lo dicho por varios ministros, lo más probable es que se descarte la aplicación de la norma restrictiva expresa. Quizá, la simple lectura de las tesis formuladas en la CT no permite tal conclusión, pero cualquier juez que leyera la totalidad de la sentencia (incluyendo los votos) no dudaría en que se trata de un caso al cual su ratio decidendi no aplica.

El caso dudoso, o prima facie, es decir, que puede parecer claro a un análisis superficial, sería el caso del arraigo. Consideramos que es superfluo recordar todos los aspectos problemáticos del arraigo. El punto central es, sin embargo, el siguiente: ¿puede o no considerarse el arraigo una figura que resulte autorizada como consecuencia de un ejercicio democrático de ponderación entre principios? Subrayo que la pregunta no hace referencia a una "buena" ponderación entre principios, sino a la existencia de algún otro valor que se pretenda satisfacer autorizando el arraigo. Que el caso sea dudoso parece confirmarlo la postura del juez constitucional francés respecto de la garde a vue, en donde afirmó que "el legislador es competente para asegurar la conciliación entre, por un lado, la prevención de los delitos y la búsqueda de los autores de las infracciones, ambas necesarias para la salvaguarda de los derechos y de los principios de valor constitucional, y, por el otro, el ejercicio de las libertades constitucionalmente garantizadas". ${ }^{67}$

67 Conseil Constitutionnel, Decisión núm. 2014-420/421 QPG, 09-10-2014, considerando 9 (traducción mía), disponible en: http://werwe.conseil-constitutionnel.fr/conseilconstitutionnel/espanol/cuestion-prioritaria-de-constitucionalidad/resoluciones/2014/decision-n2014-420-421-qpc-de-9-de-octubre-de-2014.143201.html. 
Ahora bien, lo que se desprende de la CT es que tal conciliación (restrictiva) operada por el legislador constitucional deberá dar prueba de sí en los casos concretos. Como lo afirma el ministro Zaldívar: "el problema central no se ubica en la discusión de la legitimidad de la existencia de dichas restricciones, sino más bien en la valoración caso por caso de cada una de éstas a la luz de las exigencias que impone la vigencia de un Estado democrático y constitucional de derecho". ${ }^{68}$

Hacer hincapié en la valoración de cada caso presupone una clara distinción entre normas (y restricciones) de derechos humanos entendidas abstractamente y efectos concretos de tales normas. El reciente caso del amparo en materia de arraigo ${ }^{69}$ es un ejemplo paradigmático de la diferencia entre normas y efectos, entre normas de derechos humanos y derechos humanos.

$\mathrm{Al}$ respecto, es necesario analizar la postura del ministro ponente $\mathrm{Gu}-$ tiérrez Ortiz Mena en los debates que acompañaron la resolución del amparo sobre el arraigo. ${ }^{70} \mathrm{Al}$ momento de votar sobre la cuestión de la conformidad o no a la Constitución, de la norma federal que atribuye la facultad de imponer el arraigo, el ministro precisa que a pesar de considerar, dada un cierta interpretación, la legislación federal conforme a la Constitución, tal constitucionalidad no debería llevar a negar efectos a la resolución de la Corte; a su vez, el ministro sostiene que debería remitirse el caso al tribunal colegiado, para que éste lo revise a la luz de la interpretación que, según él, salvaba la constitucionalidad de la legislación cuestionada, en particular por lo que se refiere a la utilización de las pruebas obtenidas durante el arraigo. El ministro afirma lo siguiente: "Es constitucional sí y sólo sí si se

68 Zaldívar Lelo de Larrea, Arturo, op. cit., p. XIV. Véase también Gutiérrez Ortiz Mena, Alfredo, op. cit., p. 6: "las restricciones constitucionales son heterogéneas y requieren una exploración caso por caso"; Sánchez Cordero, Olga, op. cit., p. 12. En contra Cossío Díaz, José Ramón, op. cit., p. 5: "La posición mayoritaria genera una regla universal de interpretación por virtud de la cual el derecho convencional cede frente al derecho constitucional desplazando la posibilidad de resolver los problemas caso por caso aplicando efectivamente el principio pro persona. No es verdad, como sostiene la resolución votada por la mayoría, que la interpretación generada por ella permita la ponderación caso por caso de todos los derechos humanos". La decisión en el caso del arraigo parece darle la razón al ministro Cossío.

69 ADR 1250/2012.

70 Véase ADR 1250/2012, Versión taquigráfica..., cit. En efecto, la confusión que ha caracterizado los debates es quizá la causa de la ausencia - más de un año después - del engrose. 
puede hacer un análisis de interpretación conforme, lo cual en el siguiente punto me llevaría a un efecto que revocaría la sentencia para que el colegiado analizara si los lineamientos de este Tribunal son cumplidos". ${ }^{71}$

En palabras sencillas, una cosa es la cuestión abstracta de la conformidad de una norma con lo prescrito por una norma diversa, y otra cosa son los efectos que pueden imputarse, en términos de derechos, al caso concreto.

Como subrayado, por ejemplo, por el ministro Cossío, ${ }^{72}$ el ministro Gutiérrez Ortiz Mena, a pesar de votar en el sentido de la constitucionalidad, comparte con los ministros que sostienen la inconstitucionalidad la idea sobre cuáles deberían ser los efectos de la decisión de la Corte para el caso que originó el amparo. Con independencia del resultado in abstracto, esto es, constitucionalidad o inconstitucionalidad de la legislación federal, lo que realmente importa es si el arraigo pronunciado en contra del quejoso ha sido debidamente justificado y motivado (y por lo tanto es legal), y cuáles son los efectos en materia de prueba.

La primera cuestión, relativa a la constitucionalidad, tiene que ver con las normas de derechos humanos, constitucionales o convencionales, y con las normas que establecen restricciones explícitas a los derechos humanos (en el caso específico, la restricción establecida por el artículo 16 constitucional, en donde se otorga a la "autoridad judicial, a petición del Ministerio Público y tratándose de delitos de delincuencia organizada", el poder de "decretar el arraigo de una persona", en las condiciones fijadas por la ley federal. La segunda cuestión tiene que ver con los derechos humanos (las posiciones jurídicas) de las personas sometidas a arraigo.

Si se analizan los debates que preceden el voto, resulta claro que el ministro Ortiz Mena está de acuerdo con la mayoría sobre la primera cuestión, y con la minoría sobre la segunda cuestión. In abstracto no hay viola-

71 ADR 1250/2012, Versión taquigráfica..., cit., p. 27. Se trata de una postura que, por así decirlo, corresponde a un punto resolutivo en sí mismo. La postura del ministro es lo que en Italia se conoce como "sentencia interpretativa de rechazo", una sentencia cuyo punto resolutivo central es declarar la conformidad a la Constitución de una determinada legislación, siempre y cuando se le atribuya un cierto significado, dejando entendido que cualquier otra interpretación llevaría a una violación de la Constitución.

72 Dice el ministro: "me parece que el señor Ministro Gutiérrez independientemente que haya llegado a la condición de constitucionalidad, está más cerca en los efectos, de quienes estamos por la inconstitucionalidad" (ADR 1250/2012, Versión taquigráfica..., cit., p. 37). 
ción de normas de derechos humanos, pero in concreto sí puede haber violación de derechos humanos. La forma "todo o nada" en que se plantea la cuestión de constitucionalidad genera un sinfín de malentendidos, con el ministro Ortiz a punto de cambiar su voto, ya no a favor sino en contra de la constitucionalidad. ${ }^{73}$

\section{MONISMO Y PLURALISMO: ENTRE TEORÍA Y DEREGHO POSITIVO}

La distinción entre fuentes y normas parece constituir un punto firme de la sentencia, y de ella parece depender mucho de lo que se decidió. En resumen, se ha afirmado que no existe jerarquía entre normas de derechos humanos, aunque esto no signifique que la fuente "tratado internacional" tenga en sí misma rango constitucional. Como ya he precisado al analizar la cuestión de la ausencia de jerarquía, decir que la fuente convencional en sí misma no tiene rango constitucional, puede significar dos cosas: que los tratados tienen rango subconstitucional, o que los tratados no tienen rango, esto es, que no ocupan ningún lugar en la jerarquía de las fuentes mexicanas. La aplicación de alguno de estos significados dependerá de la asunción teórica, monista o pluralista, que se haga. ${ }^{74}$

Dado que ningún ministro parece asumir claramente una perspectiva teórica, monista o pluralista, lo único que puede decirse al respecto tiene que ver con los hechos, con la realidad del derecho positivo mexicano. La realidad es ambigua, ya que el artículo 133 parece incluir a los tratados entre las fuentes del derecho mexicano, y el artículo 105 parece contemplar a los tratados en la lista de los posibles objetos de una acción de inconstitucionalidad. Pero a una lectura atenta, el artículo 133 no se limita a mencionar a los tratados sin más, pues señala que éstos van con la aprobación del Senado: su relevancia como fuente depende de la existencia de una ley mexicana de ratificación, lo que permite, a la luz de la distinción entre fuentes y normas, precisar que el tratado no es una fuente

73 "Por eso anuncié que mi voto estaba condicionado a que se hiciera una interpretación conforme y el efecto fuera devolverlo para que se analizara, si no yo cambiaría el sentido de mi voto en contra, fue precisamente por lo cual lo condicioné”. ADR 1250/2012, Versión taquigráfica..., cit., p. 30.

74 En la medida en que los ministros parecen pasar por alto que el significado de sus argumentos depende, por mucho, del punto de vista (monista o pluralista) a partir del cual hablan, el lector inexperto puede pensar que tales argumentos son entre sí conmensurable. 
de derecho mexicano hasta que una ley de ratificación haya incorporado las normas expresadas por el tratado. En consecuencia, lo que puede ser declarado inconstitucional no es el tratado, sino la ley que lo ratifica. Esto es precisamente lo que hizo el juez constitucional italiano ${ }^{75}$ respecto de la ley que ratificaba la Convención sobre las Inmunidades Jurisdiccionales de los Estados y de sus Bienes. Dada la incompatibilidad de las normas expresadas por la Convención con el derecho a la tutela jurisdiccional efectiva establecido por la Constitución italiana, se declaró inconstitucional la ley de ratificación, pero - por supuesto - la validez de la Convención misma no resultó afectada. Lo que el juez supremo italiano expulsa del sistema es la norma nacional, mas no la norma internacional derivada de la misma fuente internacional.

Si las normas constituyen el resultado de una actividad interpretativa, y las fuentes, el resultado de una actividad política de creación de derecho, es posible afirmar que el adjetivo (nacional o internacional) que se asocia a las normas depende de la autoridad que las formula a partir de la interpretación. En tal caso, una norma de derechos humanos obtenida a partir de la interpretación, por parte de un juez mexicano, de un tratado internacional sería una norma mexicana y no una norma internacional. A lo mejor puede decirse que se trata de una norma nacional de fuente internacional. En cambio, el tratado internacional en ningún sentido puede considerarse una fuente nacional, ya que sólo existe tratado si por lo menos dos Estados expresan sus voluntades.

Por lo tanto, se entiende perfectamente que no haya jerarquía entre normas de derechos humanos, no porque no exista jerarquía entre fuentes, sino porque en último análisis las normas de derechos humanos, con independencia de su fuente, son formuladas por autoridades mexicanas, y puede no haber jerarquía entre sus pronunciamientos. La confusión nace del hecho de que las referencias, tanto por el mismo texto constitucional como por la CT, a la incorporación de los tratados son tramposas. En la CT se disocian dos momentos: ${ }^{76}$ el primero es con "la incorporación de un tratado internacional al orden jurídico que tiene lugar a partir del cumplimiento de los requisitos formales de validez, los cuales se refieren fundamentalmente a la celebración del tratado internacional por el Presidente de

75 Corte Costituzionale, Sentenza 238/2014, considerando 5, disponible en: http:// wrewe.cortecostituzionale. it/actionSchedaPronuncia.do? anno $=2014$ Enumero $=238$.

76 CT, pp. 48 y 49. 
la República y su ratificación por el Senado", y un segundo momento se presenta cuando se verifica que el tratado así incorporado cumple con los requisitos formales de validez. Esta forma de distinguir los requisitos formales y materiales de validez obscurece la distinción más fundamental entre la existencia (o validez) de una fuente internacional y la existencia (o validez) de las normas por ella expresadas (en derecho nacional y/o derecho internacional, siendo que para el monista tal distinción no tendría lugar).

Resulta obvio que la ley de ratificación no constituye un requisito formal de validez del tratado. Hay que entender, por lo tanto, que se está hablando de los requisitos de validez de las normas expresadas por el texto convencional, y tales requisitos sólo condicionan la validez de dichas normas en derecho mexicano, no en general. Pero si se acepta lo anterior, no puede disociarse la validez material de la validez formal: una norma expresada por un tratado es válida en derecho mexicano, siempre y cuando: 1) el tratado haya sido válidamente celebrado; 2) la ley de ratificación del tratado sea válidamente adoptada, y, por último, 3) no es incompatible con algún criterio de validez material. Contrariamente a lo que se lee en la sentencia, si la incorporación depende de la ley de ratificación, lo que se incorpora no es el tratado, sino las normas (los contenidos) que de él pueden extraerse.

Es aquí donde la postura teórica (monista o pluralista) adquiere toda su relevancia. Si se afirma que el tratado se incorpora al derecho nacional, con ello pueden significarse dos cosas: por un lado, que el tratado, desde su existencia, es incorporado al sistema de fuentes del derecho (nacional - para el pluralista - o el único derecho - para el monista-), y por otro lado, que si una ley nacional de ratificación es adoptada, las normas expresadas por el tratado se incorporan al sistema normativo nacional. Desde una perspectiva monista, todas las fuentes se incorporan necesariamente en un único sistema; en cambio, desde una perspectiva pluralista, las normas de un sistema regulan la incorporación de normas de otros sistemas, sin que esto tenga consecuencias sobre la pertenencia de una fuente a un determinado sistema de fuentes.

Esto tiene consecuencias prácticas fundamentales, que se entienden a cabalidad si se toma en serio lo que dice Kelsen acerca de las normas derogatorias. ${ }^{77}$ Cuando el legislador nacional decide derogar una legislación anterior, nadie se sorprende. Una norma válida derogatoria suprime la

77 Kelsen, Hans, "Derogación", op. cit. 
validez de una norma que deja así de ser válida. En términos de derechos positivos, la cuestión de la unidad o pluralidad depende, en mi opinión, de la existencia de normas derogatorias. ${ }^{78} \mathrm{Si}$ una norma constitucional mexicana autoriza la derogación de una norma convencional, entonces la Constitución y el tratado derogado constituyen un solo sistema, en donde manifiestamente la autoridad constitucional es jerárquicamente superior a la autoridad internacional. Análogamente podría darse la situación inversa; por ejemplo, que un tribunal internacional pueda derogar o suprimir la validez de una norma constitucional nacional.

En el plano del derecho positivo, con independencia de la jerarquía que se tome por "verdadera", y a pesar de adoptar una perspectiva monista, hay que reconocer que el derecho, ya sea constitucional o internacional, no cuenta con normas sobre la derogación para los casos de conflictos entre normas internacionales y normas constitucionales. Salvo crasa ignorancia de mi parte, no existe ninguna norma constitucional mexicana que - por ejemplo - establezca que una norma interamericana en conflicto con una disposición constitucional mexicana pierde su validez; tampoco hay una norma interamericana que establezca que una norma constitucional nacional pierde su validez cuando entra en conflicto con una norma interamericana. ${ }^{79}$

Sobre este último punto, la misma Corte Interamericana, a pesar de haber sostenido que las leyes contrarias al objeto y fin de la Convención "desde un inicio carecen de efectos jurídicos", ${ }^{80}$ ha claramente afirmado que es obligación del Estado la supresión de las normas o prácticas inconvencionales. ${ }^{81}$ Si no fueran normas válidas (esto es, si el simple hecho de la

78 En contra, sin embargo, Kelsen, Hans, Teoría pura..., cit., cap. V. Según este autor, dos normas jurídicas, una de las cuales autoriza directa o indirectamente a la otra, pertenecen al mismo sistema jurídico.

79 A pesar de ello, algunos autores no dudan en hablar de revisión o impugnación de sentencias dictadas por la SCJN, por tribunales internacionales. Véase Bustillos, Juan, "Caso Radilla. Paradigma de la protección constitucional de los derechos humanos frente a la responsabilidad del Estado mexicano", Boletín Mexicano de Derecho Comparado, núm. 135, septiembre-diciembre de 2012, p. 998.

80 Corte IDH, Caso Almonacid Arellano y otros vs. Chile. Excepciones preliminares, fondo, reparaciones y costas. Sentencia del 26 de septiembre de 2006, Serie C, núm. 154, párr. 124.

81 Corte IDH, Caso Heliodoro Portugal vs. Panamá. Excepciones preliminares, fondo, reparaciones y costas. Sentencia del 12 de agosto de 2008, Serie C, núm. 186, párr. 180. 
incompatibilidad le quitara su validez), no deberían (en el sentido de: no sería necesario) ser eliminadas. En el mismo sentido debe entenderse lo que afirma Nogueira Alcalá: si el juez nacional tiene "competencia anulatoria o derogatoria de normas contrarias a la Constitución, si es que el parámetro de control de constitucionalidad integra los derechos convencionales, dicho órgano jurisdiccional debería expulsar la norma interna contraria a tales derechos" ${ }^{82}$ Pero, como diría Kelsen, tanto que dicha autoridad no la expulsa, la norma interna incompatible sigue perfectamente válida, y su ejecución continúa siendo exigible.

Si el derecho mexicano, como sospecho, es esencialmente dualista, ninguna cuestión seria de jerarquía entre fuentes internas e internacionales debería plantearse. El derecho internacional, en general, no existe como norma sin que algún acto jurídico estatal le haya dado "vida". Una vez que se le haya dado vida, sí puede plantearse la cuestión del estatus de las normas así incorporadas. Pero tales normas deben de atribuirse a la autoridad cuyo acto ha establecido la incorporación. Ahora bien, la conclusión es simple: en el derecho mexicano, mientras las normas incorporadas a partir de los tratados en general tienen la jerarquía de la ley que los ratificó, ${ }^{83}$ las normas de derechos humanos de fuente internacional - en cambio - tienen jerarquía constitucional en virtud de la autoridad que las incluyó en el parámetro de constitucionalidad, esto es, el poder constituyente derivado (o la SCJN, lo que, en términos de jerarquía, da lo mismo).

La supremacía constitucional no está en juego. Tal supremacía, a la luz de lo anterior, tiene dos sentidos: 1) significa supremacía de la Constitución sobre las demás fuentes del derecho mexicano (incluidas las leyes que ratifican tratados), y 2) significa supremacía del sistema jurídico mexicano, cuyo fundamento de validez es la Constitución, sobre los demás sistemas jurídicos. Según un monista, sólo puede haber un sistema jurídico, y en tal caso la supremacía que para un pluralista se refiere a otros

82 Nogueira Alcalá, Humberto, "Los desafíos del control de convencionalidad del corpus iuris interamericano para las jurisdicciones nacionales", Boletín Mexicano de Derecho Comparado, núm. 135, septiembre-diciembre de 2012, p. 1187.

83 En este sentido se pronuncia, por ejemplo, la Corte Constitucional italiana: "Con respecto a las disposición de la CEDH... a falta de una especifica provisión constitucional, las mismas, aplicables en el ordenamiento interno en virtud de una ley ordinaria, de ella adquieren el rango y por lo tanto no se ubican en el nivel constitucional”. Corte Costituzionale, Sentenza n. 349/2007, considerando 6.1, disponible en: http://wrere.cortecostituzionale. it/actionSchedaPronuncia.do? anno $=2007$ Enumero $=349$. 
sistemas, para el monista debe referirse a otras fuentes del mismo sistema. Pero esto nada cambia a la cuestión de la supremacía.

\section{CONCLUSIÓN}

Una conclusión provisoria es, entonces, que el de la jerarquía es un falso problema o un problema real insuficientemente planteado (lo que lo condena a no encontrar una solución). Que sea un falso problema resulta del núcleo de la discusión cuyo punto central es resolver la cuestión sobre qué norma aplicar. La respuesta a tal cuestión es potencialmente independiente de la jerarquía de fuentes; es decir, que podría existir el deber de aplicar una norma que es, desde el punto de vista formal, jerárquicamente subordinada. Por ejemplo, según la Corte Constitucional italiana, no hay dudas sobre el rango subconstitucional de las normas expresadas por el Convenio Europeo de Derechos Humanos, pero esto no significa que la incompatibilidad de una norma legislativa con tales normas no pueda justificar una pronuncia de inconstitucionalidad. ${ }^{84}$

El auténtico problema se ubica en el terreno interpretativo y, sobre todo, en el nivel de la aplicación del derecho en cada caso concreto. El espíritu que parece haber dirigido la CT parece relativamente sensato, y no sorprende que pueda formularse con palabras de otro juez supremo: se trata de realizar un "correcto balance entre la exigencia de garantizar el respeto, exigido por la Constitución, de las obligaciones internacionales y la de evitar que esto pueda implicar por otro lado una vulneración de la Constitución misma". ${ }^{85}$

Este balance se hace, inevitablemente, no en el plano de la jerarquía formal, sino en el plano de la interpretación y aplicación del derecho. El desacuerdo real, que la CT no resuelve, termina siendo el siguiente: ¿una disposición constitucional restrictiva de derechos humanos entra en el juego interpretativo o puede pretender su aplicación con la automática exclusión de todas las disposiciones protectoras? Como he esperado mostrar, la respuesta depende mucho de la naturaleza de la norma expresada por la disposición restrictiva: 1) si se trata de una limitación del campo de aplicación de un principio, inevitablemente habrá que ponderar, lo

84 Corte Costituzionale, Sentenza n. 349/2007, considerando 6.2.

85 Idem. 
que significa que la restricción entrará en un balance en donde quizá las normas protectoras podrían tener más peso, por lo menos en ciertos casos concretos, y 2) si se trata de una regla, parece más plausible que su aplicación torne superfluo el juego de la ponderación, y esto en virtud de una intuición sencilla, según la cual "lo que señala el artículo $1^{\circ}$ constitucional es preferir la interpretación —y no la aplicación-, más favorable". ${ }^{86}$

A pesar de excluir la ponderación, parece posible - salvo aceptar una teoría formalista de la interpretación- que los jueces operen una interpretación conforme del texto restrictivo. El caso del arraigo parece, sin embargo, ir en el sentido de una aplicación casi mecánica de la restricción constitucional; pero la decisión fue tomada por una mayoría de seis ministros, con uno de ellos, el ministro Gutiérrez Ortiz Mena, ${ }^{87}$ que manifiestamente se abocó por la tesis de la interpretación conforme. Para volver a Kelsen - y dar cuerpo a su decisionismo - un corolario de todo lo anterior es que dada la ambigüedad del texto constitucional y la cantidad de posibles distinciones que funcionan como multiplicadores de las dificultades interpretativas, lo más probable es que cuestiones como la que tuvo que resolver la SCJN pueden ser solucionadas de cualquier forma, siendo el único criterio el juego frágil de la formación de mayorías. Frente a un conflicto, los tribunales supremos competentes, en ámbito nacional o internacional, podrán decidir, esencialmente, cualquier cosa. Así, cualquier decisión podría ser juzgada, a partir de una combinación ad hoc de definiciones y elecciones interpretativas, como adecuada.

La única conclusión legítima es, entonces, que habrá que esperar otras decisiones para saber cómo se decanta la postura, por lo menos mayoritaria, de los ministros. Aun así, en este trabajo espero haber demostrado que la otra cuestión que ha monopolizado la atención de los ministros y de la doctrina (sobre la jerarquía) ha sido planteada de manera insuficiente y, de todas formas, termina sin tener consecuencias prácticas relevantes en cuanto a la garantía efectiva de los derechos humanos. Pero, sobre todo, espero que se haya difuminado completamente la falsa creencia sobre la existencia, en este nivel de complejidad constitucional, de respuestas correctas; ojalá que se deje de hablar de una decisión de la SCJN como posiblemente inconstitucional, como si la Constitución fuera alguna entidad a priori con un contenido autoevidente y obligatorio para los jueces. Esto no

86 Aguilar Morales, Luis María, op. cit., p. 9.

87 ADR 1250/2012, Versión taquigráfica..., cit. 
Esta revista forma parte del acervo de la Biblioteca Jurídica Virtual del Instituto de Investigaciones Jurídicas de la UNAM

significa que no se pueda criticar una decisión, pero no por su inexactitud o no reconocimiento de ciertas verdades constitucionales (o peor: interamericanas). Lo único criticable es la falta de claridad en los argumentos; sin embargo, esto no es imputable a los ministros, sino a la forma en que está organizado el trabajo de la Corte, y en particular a la institución del engrose, que en lugar de ser el reflejo de un cristalino razonamiento, se parece más a un monstruo de once cabezas. No obstante, entre los juristas serios, ¿quién, en un caso así, se limitaría a leer el engrose? Creo que nadie. Además, la lectura de los votos — sospecho- permite reconstruir virtualmente una votación que no tuvo lugar, pero que es indudablemente real: la mayoría de los ministros, en definitiva, piensan que más allá de las tesis votadas y publicadas, los jueces mexicanos deberán decidir caso por caso, y cumplirán con la sentencia en la medida en que darán cuenta de las razones por las cuales consideran que tal o cual restricción, en un determinado caso, aplica o no. 